\title{
Effects of pomegranate supplementation on exercise performance and post-exercise recovery in healthy adults: a systematic review
}

\author{
Achraf Ammar ${ }^{1,2_{*}}$, Stephen J. Bailey ${ }^{3}$, Hamdi Chtourou ${ }^{4}$, Khaled Trabelsi ${ }^{4}$, Mouna Turki ${ }^{1}$, \\ Anita Hökelmann ${ }^{2}$ and Nizar Souissi ${ }^{5}$ \\ ${ }^{1}$ Laboratory of Biochemistry, CHU Habib Bourguiba, Sfax University, 3000 Sfax, Tunisia \\ ${ }^{2}$ Institute of Sport Science, Otto-von-Guerick University, 39106 Magdeburg, Germany \\ ${ }^{3}$ School of Sport, Exercise and Health Sciences, Loughborough University, Loughborough LE11 3TU, UK \\ ${ }^{4}$ High Institute of Sport and Physical Education of Sfax, Sfax University, 3000 Sfax, Tunisia \\ ${ }^{5}$ National Observatory of Sport, 1003 Tunis, Tunisia \\ (Submitted 11 April 2018 - Final revision received 13 August 2018 - Accepted 21 August 2018 - First published online 23 October 2018)
}

\section{Abstract}

The functional significance of pomegranate (POM) supplementation on physiological responses during and following exercise is currently unclear. This systematic review aimed (i) to evaluate the existing literature assessing the effects of POM supplementation on exercise performance and recovery; exercise-induced muscle damage, oxidative stress, inflammation; and cardiovascular function in healthy adults and (ii) to outline the experimental conditions in which POM supplementation is more or less likely to benefit exercise performance and/or recovery. Multiple electronic databases were used to search for studies examining the effects of POM intake on physiological responses during and/or following exercise in healthy adult. Articles were included in the review if they investigated the effects of an acute or chronic POM supplementation on exercise performance, recovery and/or physiological responses during or following exercise. The existing evidence suggests that POM supplementation has the potential to confer antioxidant and anti-inflammatory effects during and following exercise, to improve cardiovascular responses during exercise, and to enhance endurance and strength performance and post-exercise recovery. However, the beneficial effects of POM supplementation appeared to be less likely when (i) unilateral eccentric exercise was employed, (ii) the POM administered was not rich in polyphenols $(<1.69 \mathrm{~g} / \mathrm{l})$ and (iii) insufficient time was provided between POM-ingestion and the assessment of physiological responses/performance $(\leq 1 \mathrm{~h})$. The review indicates that POM has the potential to enhance exercise performance and to expedite recovery from intensive exercise. The findings and recommendations from this review may help to optimise POMsupplementation practice in athletes and coaches to potentially improve exercise-performance and post-exercise recovery.

Key words: Sports nutrition: Polyphenols: Oxidative stress: Muscle damage: Inflammation

Pomegranate (POM) or Punica granatum is an ancient fruit originating from the Middle East ${ }^{(1)}$. The POM fruit is berrylike with a leathery rind enclosing many seeds surrounded by the juicy arils, which comprise the edible portion of the fruit $^{(2)}$. This edible part represents approximately $52 \%$ of total fruit weight, comprising $78 \%$ juice and $22 \%$ seeds $^{(3)}$. Dietary supplementation with POM fruit has traditionally been consumed as pomegranate juice (POMj) obtained from the first-press (partial pressing) squeezing of whole POM fruits $^{(4)}$. More recently, pomegranate extract (POMe) has been developed in liquid and dry powder forms to provide alternative convenient sources for obtaining the bioactive polyphenols found in POMj. The liquid POMe is produced by extraction of the remaining fruit residue obtained, after an additional pressing, and the powdered POMe is obtained from further resin purification and drying (solid-phase extraction) to produce a powder with a high concentration of polyphenols $^{(4)}$.

Dietary supplementation with POMj or POMe, which are both rich in polyphenols, has been reported to promote several beneficial health effects ${ }^{(5,6)}$. In particular, POM supplementation appears to be effective at enhancing physiological responses in individuals exhibiting physiological stress such as $\mathrm{CVD}^{(7)}$, oxidative stress $^{(8)}$, cellular inflammation ${ }^{(9)}$ or joint or

Abbreviations: ASAT, aspartate aminotransferase; BF, blood flow; CK, creatine kinase; CRP, C-reactive protein; DOMS, delayed onset muscle soreness; HR, heart rate; hs-CRP, high-sensitivity C-reactive protein; LDH, lactate dehydrogenase; MDA, malondialdehyde; MMP, matrix metalloproteinase; NO, nitric oxide; PC, protein carbonyl; PLA, placebo; POM, pomegranate; POMe, pomegranate extract; POMj, pomegranate juice; ROS, reactive oxygen species; SBP, systolic blood pressure; VD, vessel diameter.

* Corresponding author: A. Ammar, email ammar.achraf@ymail.com 
muscle damage ${ }^{(10,11)}$. Indeed, POM consumption has been reported to lower CVD morbidity by enhancing myocardial blood flow (BF, 17\%) ${ }^{(12)}$ and antioxidant status $(130 \%)^{(7)}$, and lowering LDL-cholesterol oxidation (-90\%), systolic blood pressure (SBP, $-12 \%)$, and carotid artery thickness $(-30 \%)^{(7)}$. Similarly, POM has been shown to attenuate oxidative stress by lowering free radical production and lipid peroxidation $(-65 \%)^{(13)}$, and to inhibit some cellular inflammation transcripts $^{(14,15)}$ such as NF- $\kappa \mathrm{B}$, TNF- $\alpha$ and cyclo-oxygenase-2 (COX-2). Since, these positive physiological effects afforded by POM supplementation have the potential to prevent or treat various disease risk factors, POM has been described as a 'super fruit' ${ }^{\text {'(14) }}$. In this context, and compared with other purported nutraceuticals (e.g. green tea, red wine, orange, blueberry and cranberry juices), POM supplements have been reported to confer the most potent antioxidant and antiinflammatory effects ${ }^{(13,16)}$. Indeed, compared to the aforementioned foods, POMj is more effective in attenuating LDL oxidation and inhibiting cellular oxidative stress in macrophages. Moreover, POMj exhibits a high capacity to neutralise free radicals with a reported antioxidant activity three times higher than of red wine and green tea (Trolox equivalent antioxidant capacity $=18-20 v \cdot 6-8)^{(16)}$. POM also possesses a higher antioxidant activity compared to other food stuffs such as turmeric, ragi, amla, amaranth, rajmah, sesame, wheat and flaxseed $^{(13)}$. Although the underlying mechanisms for the beneficial physiological (e.g. antioxidant, anti-damaging and anti-inflammatory) effects of POM supplementation, are not yet clear ${ }^{(17-19)}$, its efficacy has been attributed to the high bioavailability of its constituent polyphenols compared to other polyphenol-rich foods ${ }^{(5,16)}$

Physical exercise is a potent and multifaceted physiological stressor, as evidenced by an immediate increase in markers of muscle damage ${ }^{(20-23)}$, inflammation and oxidative stress ${ }^{(23,24)}$ and a protracted period of muscle weakness and soreness during the post-exercise recovery period ${ }^{(17,25)}$. Since POM supplementation appears particularly effective at improving numerous physiological responses in individuals manifesting symptoms of physiological stress ${ }^{(7,12-14)}$, POM supplementation might have potential as an ergogenic and recovery aid. Notwithstanding this potential for enhanced exercise performance and post-exercise recovery following POM supplementation, studies assessing the effects of POM supplementation on exercise performance and recovery are limited and yield equivocal findings ${ }^{(17-19,25-27)}$.

The aims of the present systematic review were (i) to examine the effect of POM intake on exercise performance and recovery, as well as its acute and delayed effects on muscle damage, oxidative stress, inflammation and cardiovascular function following exercise in healthy individuals and (ii) to outline how aspects of the study design (e.g. fitness status of participants, biomarkers assessed, supplement dose and exercise protocol) can influence the potential ergogenic and recuperative effects of POM supplementation. The recommendations from this review will have the potential to inform POM supplementation guidelines to optimise exercise performance and recovery practices in athletes and sports nutritionist

\section{Methods}

This systematic review was conducted and reported in accordance with the guidelines of the preferred reporting items for systematic reviews and meta-analyses statement, which is an evidence-based protocol describing a set of items for reporting in systematic reviews and meta-analyses ${ }^{(28)}$.

\section{Data sources and search strategy}

To inform our review, a comprehensive systematic search of studies was performed electronically in the following databases: PubMed/Medline, Web of Science and science direct from inception to January 2018. The search was limited to English language. The following search terms and Medical Subject Headings (MeSH) were used to source articles from pertinent peer-reviewed journals: Pomegranates (MeSH) OR Pomegranates (All Fields) OR Pomegranate (All Fields) OR Punicagranatum (All Fields) OR Punicagranatums (All Fields) OR granatum, Punica (All Fields) AND exercise (MeSH) OR exercise (All Fields) OR exercises (All Fields). The search was supplemented by manually cross-matching reference lists, key author searches, and citation searching of all retrieved papers to potentially identify additional studies. The search strategies were combined, and duplicates were removed by Endnote and manually by two of the authors. Once all relevant articles had been located, the researcher individually considered each article for its appropriateness for inclusion based on the predetermined inclusion criteria described below. Where there was uncertainty with regard to inclusion, discussion with a third researcher determined the final inclusion or exclusion of the article.

\section{Inclusion and exclusion criteria}

To be included in the systematic review, individual studies needed to fulfill the following inclusion criteria: (i) primary research published in peer-reviewed journals in English, (ii) research conducted with healthy human participants (sedentary, active or trained subjects), (iii) original studies that had investigated an acute or long-term POM supplementation intervention (juice or extract) on performance and/or physiological responses, (iv) no severe methodological deficiencies (e.g. absence of placebo (PLA) control, participant were not blinded, inappropriate statistical analysis procedures) and (v) published before February 2018. Exclusion criteria were: (i) studies written in languages other than English, (ii) data from congress or workshop publications, (iii) animal studies, (iv) studies in which no supplementation was given, (v) studies which administered multiple supplements in addition to POM as this thwarted clear separation of the effects of POM from the other supplements, (vi) studies in which no exercise was performed and (vii) studies in which exercise was performed in extreme environments (e.g. altitude, heat, etc.). No limits were set for the year of publication. Case studies, encyclopaedia, book chapters and reviews were excluded, although the bibliographies of the latter were consulted to refine article searches. 


\section{Study selection}

Following the removal of duplicate studies from the different search engines, inclusion or exclusion of the remaining articles was performed by applying the above criteria on the title and abstract to determine eligibility in a preliminary independent screening. Selected papers were then read in full to finalise eligibility or exclusion. A summary of this process is outlined in Fig. 1. The university's library, hand searches, electronical databases and contact with the authors were used to obtain full copies of the published manuscripts.

\section{Data extraction}

Data were extracted using a standardised form. The primary outcomes extracted in this review were the effects of POM supplementation on physical performance, fatigue, and perception of pain and soreness (e.g. rating of perceived exertion (RPE), delayed onset muscle soreness (DOMS), pain scale) during and/or following exercise. These outcomes are presented in Table 1. All data concerning the effect of POM supplementation on muscle damage (e.g. the concentrations of creatine kinase (CK), lactate dehydrogenase (LDH), myoglobin (Mb), aspartate aminotransferase (ASAT)), oxidative stress (e.g. thiobarbituric acid-reactive substances (TBARS), malondialdehyde (MDA), protein carbonyl (PC), total antioxidant capacity (TAC), glutathione peroxidase (GPX), superoxide dismutase (SOD), catalase (CAT), uric acid (UA), arylesterase), inflammatory (e.g. C-reactive protein (CRP), high-sensitivity C-reactive protein (hs-CRP), IL-6, matrix metalloproteinases (MMP), sE-selectin, leucocytes) and cardiovascular (e.g. heart rate (HR), blood pressure, BF, vessel diameter (VD), oxygen saturation) responses following exercise were extracted from the research papers and are shown in Table 2. For all extracted performance and physiological data (Tables 1 and 2), the effects of POM supplementation were separated into data collected (i) during and immediately (up to $2 \mathrm{~h}$ ) after exercise, which we classified as acute responses and (ii) after a period of at least $24 \mathrm{~h} / 48 \mathrm{~h}$ following exercise, which we classified as delayed responses ${ }^{(17-19,22-25)}$.

\section{Quality assessment}

To assess the methodological quality of the selected studies, the Physiotherapy Evidence Database (PEDro) scale was used ${ }^{(29)}$. The PEDro scale is based on the Delphi list developed by Verhagen et al. ${ }^{(30)}$ at the Department of Epidemiology, University of Maastricht. The PEDro scale is a reliable and objective tool that helps identify which of the randomised clinical trials from the same areas of physiotherapy practice are likely to be externally (criteria 1) and internally (criteria 2-9) valid and could have sufficient statistical information to make their results interpretable (criteria 10 and 11$)^{(29)}$. Each paper was independently assessed twice by two independent reviewers using the eleven-item checklist to yield a maximum score of 10 (the sum of awarded points for criteria 2-11). Points are only awarded when a criterion is clearly satisfied. In case of disagreements concerning trial scoring, a discussion with a third reviewer was conducted. The level of agreement between reviewers was calculated via the $\kappa$ values with $k=0.91$ indicating an excellent agreement $^{(31)}$.

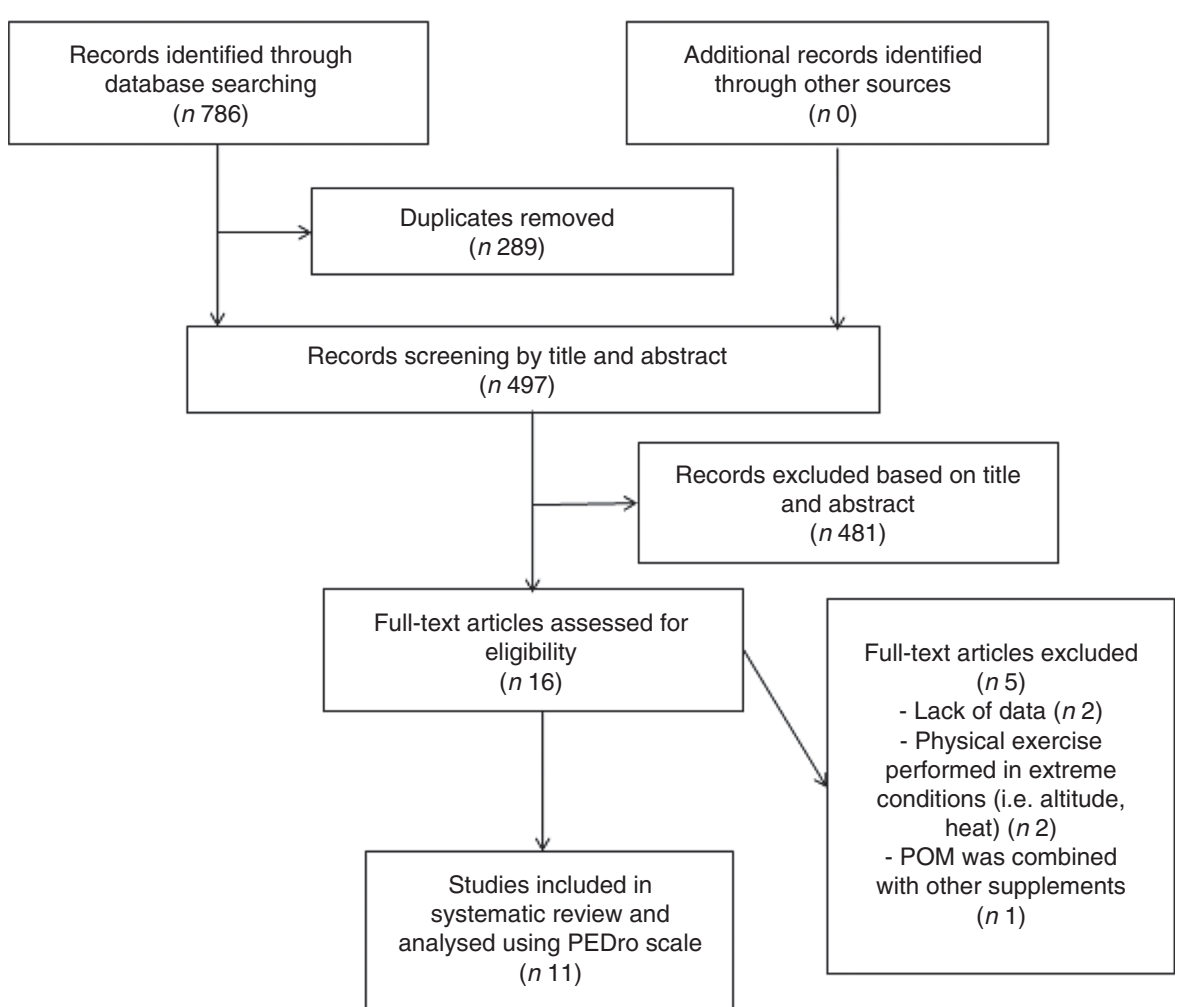

Fig. 1. Flowchart of study selection. PEDro, physiotherapy evidence database scale; POM, pomegranate. 
Table 1. Effect of pomegranate (POM) on physical performance and fatigue and muscle soreness responses following exercise (ex)

\begin{tabular}{|c|c|c|c|c|c|c|c|c|c|}
\hline & & & & & & & \multicolumn{3}{|c|}{ POM effect on: } \\
\hline \multicolumn{7}{|c|}{ Study design } & \multirow[b]{2}{*}{ Performance } & \multicolumn{2}{|c|}{ Fatigue/soreness } \\
\hline Authors & Subjects & Dosage & Duration & Design & $\begin{array}{l}\text { Phenol } \\
\text { content }\end{array}$ & Exercise protocol & & Acute & Delayed \\
\hline $\begin{array}{l}\text { Trombold } \\
\quad \text { et al. }\end{array}$ & $\begin{array}{l}\text { Sixteen } \\
\quad \text { recreationally } \\
\text { active males }\end{array}$ & $\begin{array}{c}2 \times 0.5 \text { litre } / \mathrm{d} \mathrm{POMj} \\
12 \mathrm{~h} \text { interval }\end{array}$ & $\begin{array}{l}9 \mathrm{~d}(4 \mathrm{~d} \text { prior, } 5 \mathrm{~d} \\
\quad \text { after ex) }\end{array}$ & $\begin{array}{l}\text { Double-blind, randomised, } \\
\text { PLA-controlled crossover } \\
\text { design ( } 14 \mathrm{~d} \text { washout) }\end{array}$ & $\begin{array}{l}0.66 \mathrm{~g} / 0.5 \\
\text { litre }\end{array}$ & $\begin{array}{l}\text { Unilateral eccentric elbow } \\
\text { flexion }(2 \times 20)\end{array}$ & $\begin{array}{l}\uparrow \text { Elbow flexor (i.e. } \\
\text { strength) at } 48 \text { and } \\
72 \mathrm{~h} \text { post-ex }\end{array}$ & $\begin{array}{l}\text { DOMS: } \downarrow \text { elbow flexor } \\
\text { at } 2 \mathrm{~h} \text { post-ex }\end{array}$ & $\begin{array}{l}\text { DOMS: } \leftrightarrow \text { elbow } \\
\text { flexor at } 24- \\
96 \mathrm{~h} \text { post-ex }\end{array}$ \\
\hline $\begin{array}{l}\text { Trombold } \\
\text { et al. }{ }^{(17)}\end{array}$ & $\begin{array}{l}\text { Seventeen } \\
\text { resistance trained } \\
\text { males }\end{array}$ & $\begin{array}{l}2 \times 0.25 \text { litre } / \mathrm{d} \\
\text { POMj, } 12 \mathrm{~h} \\
\text { interval }\end{array}$ & $\begin{array}{l}15 \mathrm{~d}(7 \mathrm{~d} \text { prior, } 8 \mathrm{~d} \\
\text { after ex) }\end{array}$ & $\begin{array}{l}\text { Double-blind, randomised, } \\
\text { PLA-controlled crossover } \\
\text { design ( } 14 \mathrm{~d} \text { washout) }\end{array}$ & $\begin{array}{l}0.66 \mathrm{~g} / 0.5 \\
\text { litre }\end{array}$ & $\begin{array}{l}\text { Unilateral eccentric: elbow- } \\
\text { flexion }(2 \times 20) \text {; knee- } \\
\text { extension }(6 \times 10)\end{array}$ & $\begin{array}{l}\uparrow \text { Elbow flexor (i.e. } \\
\text { strength) up to } 168 \mathrm{~h} \\
\text { post-exercise; } \\
\leftrightarrow \text { knee extensor }\end{array}$ & $\begin{array}{l}\text { DOMS: } \leftrightarrow \text { elbow } \\
\quad \text { flexor and knee } \\
\text { extensor at } 2 \mathrm{~h} \\
\text { post-ex }\end{array}$ & $\begin{array}{l}\text { DOMS: } \downarrow \text { elbow } \\
\quad \text { flexor at } 48 \\
\text { and } 72 \mathrm{~h} \text { post- } \\
\text { ex; }\end{array}$ \\
\hline $\begin{array}{l}\text { Machin } \\
\text { et al. }\end{array}$ & $\begin{array}{l}\text { Forty-five } \\
\text { recreationally } \\
\text { active males }\end{array}$ & $\begin{array}{l}1 \times \text { or } 2 \times 0.5 \text { litre } / d \\
\text { POMj }\end{array}$ & $\begin{array}{l}8 \mathrm{~d}(4 \mathrm{~d} \text { prior, } 4 \mathrm{~d} \\
\quad \text { after ex) }\end{array}$ & $\begin{array}{l}\text { Double-blind, randomised, } \\
\text { PLA-controlled, three arms } \\
\text { design }\end{array}$ & $\begin{array}{l}0.65 \mathrm{~g} / 0.5 \\
\text { litre }\end{array}$ & $\begin{array}{l}\text { Ten sets }(\times 2 \mathrm{~min}) \text { downhill } \\
\text { running }+40 \text { bilateral } \\
\text { eccentric elbow flexion }\end{array}$ & $\begin{array}{l}\uparrow \text { Strength recovery of } \\
\text { both arm and leg } \\
\text { muscles }\end{array}$ & & \\
\hline $\begin{array}{l}\text { Trexler } \\
\quad \text { et al. }{ }^{(32)}\end{array}$ & $\begin{array}{l}\text { Nineteen (ten males, } \\
\text { nine females), } \\
\text { highly active }\end{array}$ & $1000 \mathrm{mg}, \mathrm{POMe}$ & 30 min pre-ex & $\begin{array}{l}\text { Double-blind, randomised, } \\
\text { PLA-controlled crossover } \\
\text { design ( } 7 \mathrm{~d} \text { washout) }\end{array}$ & & $\begin{array}{l}\text { Three TTE at 90, } 100 \text { and } \\
110 \% \text { PV }\end{array}$ & $\begin{array}{l}\uparrow \text { Sub-maximal aerobic } \\
\text { performance (TTE } \\
\text { at } 90 \text { and } 100 \%) ; \\
\leftrightarrow \text { anaerobic running } \\
\text { capacity, critical } \\
\text { velocity, TTE at } \\
110 \%\end{array}$ & $\begin{array}{l}\leftrightarrow \text { Visual analogue } \\
\text { pain scale; } \\
\uparrow \text { vitality scale }\end{array}$ & \\
\hline $\begin{array}{l}\text { Ammar } \\
\text { et al. }\end{array}$ & $\begin{array}{l}\text { Nine elite weight- } \\
\text { lifters }\end{array}$ & $\begin{array}{l}0.5 \text { litre } 1 \mathrm{~h} \text { prior } \\
\text { ex }+1.5 \text { litres } \\
48 \mathrm{~h} \text { post-ex } \\
(3 \times 0.25 \text { litre } / \mathrm{d} \\
8 \mathrm{~h} \text { interval) }\end{array}$ & $\begin{array}{l}1 \mathrm{~h} \text { pre-ex and } 2 \mathrm{~d} \\
\text { post-ex }\end{array}$ & $\begin{array}{l}\text { Double-blind, non- } \\
\text { randomised, PLA- } \\
\text { controlled crossover design } \\
\text { (48 h washout) }\end{array}$ & $\begin{array}{l}2.56 \mathrm{~g} / 0.5 \\
\text { litre }\end{array}$ & $\begin{array}{l}\text { Intense weightlifting training } \\
\text { session }\end{array}$ & $\begin{array}{l}\uparrow \text { Total and maximal } \\
\text { load lifted }\end{array}$ & $\begin{array}{l}\downarrow \text { Perception of } \\
\text { muscle fatigue } \\
\text { values (RPE) }\end{array}$ & $\begin{array}{l}\text { DOMS: } \downarrow \text { knee } \\
\text { extensor; } \\
\leftrightarrow \text { elbow flexor at } \\
\text { 48 host-ex }\end{array}$ \\
\hline $\begin{array}{l}\text { Roelofs } \\
\text { et al. }{ }^{(35)}\end{array}$ & $\begin{array}{l}\text { Nineteen (eight } \\
\text { males, eleven } \\
\text { females) } \\
\text { recreationally } \\
\text { resistance-trained }\end{array}$ & $1000 \mathrm{mg}, \mathrm{POMe}$ & $\begin{array}{c}30 \text { min prior } \\
\text { exercise }\end{array}$ & $\begin{array}{l}\text { Double-blind, randomised, } \\
\text { PLA-controlled crossover } \\
\text { design ( } 7 \mathrm{~d} \text { washout) }\end{array}$ & $\underset{\mathrm{I}}{3500 \mu \mathrm{mol} /}$ & $\begin{array}{l}\text { High-intensity exercises } \\
\text { (i.e. RSA, RTF at } 80 \% \\
\text { on bench and leg press) }\end{array}$ & $\begin{array}{l}\uparrow \text { Average and peak } \\
\text { power only in sprint } \\
5 \text { of the RSA } \\
\leftrightarrow \text { RTF on bench and } \\
\text { leg press }\end{array}$ & & \\
\hline
\end{tabular}

POMj, pomegranate juice; PLA, placebo; $\uparrow$, significant increase using POM supplementation compared with PLA; DOMS, delayed onset muscle soreness; $\downarrow$, significant decrease using POM supplementation compared with PLA; $\leftrightarrow$, no significant difference between POM and PLA conditions; POMe, pomegranate extract; TTE, treadmill runs to exhaustion; PV, peak velocity; RPE, rating of perceived exertion; RSA, repeated sprint ability; RTF, repetitions to fatigue. 
Table 2. Effect of pomegranate (POM) on muscle damage, oxidative stress, inflammatory and cardiovascular responses following exercise (ex)

\begin{tabular}{|c|c|c|c|c|c|c|c|c|c|c|c|c|c|c|}
\hline & & & & & & & \multicolumn{8}{|c|}{ POM effect on: } \\
\hline \multicolumn{7}{|c|}{ Study design } & \multicolumn{2}{|c|}{ Muscle damage } & \multicolumn{2}{|c|}{ Oxidative stress } & \multicolumn{2}{|c|}{ Inflammation } & \multicolumn{2}{|c|}{ Cardiovascular } \\
\hline Authors & Subjects & Dosage & Duration & Design & $\begin{array}{l}\text { Phenol } \\
\text { content }\end{array}$ & Exercise protocol & Acute & Delayed & Acute & Delayed & Acute & Delayed & Acute & Delayed \\
\hline $\begin{array}{l}\text { Trombold } \\
\text { et al. }{ }^{(25)}\end{array}$ & $\begin{array}{l}\text { Sixteen } \\
\text { recreationally } \\
\text { active males }\end{array}$ & $\begin{array}{l}2 \times 0.5 \text { litre } / \mathrm{d} \\
\text { POMj }\end{array}$ & $\begin{array}{l}9 \mathrm{~d}(4 \text { pre- and } \\
5 \text { post-ex) }\end{array}$ & $\begin{array}{l}\text { Double-blind, } \\
\text { randomised, } \\
\text { PLA-controlled } \\
\text { crossover (14 d } \\
\text { washout) }\end{array}$ & $\begin{array}{l}0.66 \mathrm{~g} / 0.5 \text { litre } \\
\text { POMj }\end{array}$ & $\begin{array}{l}\text { Unilateral eccentric } \\
\text { elbow flexion } \\
(2 \times 20)\end{array}$ & $\begin{aligned} & \leftrightarrow \mathrm{CK}, \mathrm{MB} \\
& \text { at } 2 \mathrm{~h} \\
& \text { post-ex }\end{aligned}$ & $\begin{array}{l}\leftrightarrow \mathrm{CK}, \mathrm{MB} \\
\quad \text { after } 1-4 \mathrm{~d}\end{array}$ & & & $\begin{array}{l}\leftrightarrow \text { IL-6, hs- } \\
\text { CRP, } 2 \text { h } \\
\text { post-ex }\end{array}$ & $\begin{array}{l}\leftrightarrow \text { hs-CRP, } \\
\text { IL-6, after 1- } \\
4 \mathrm{~d}\end{array}$ & & \\
\hline $\begin{array}{l}\text { Tsang } \\
\text { et al. }{ }^{(34)}\end{array}$ & $\begin{array}{l}\text { Twenty } \\
\text { recreationally } \\
\text { active }\end{array}$ & 0.5 litre/d POMj & 1 week pre-ex & $\begin{array}{l}\text { Double-blind, } \\
\text { randomised } \\
\text { PLA- } \\
\text { controlled, two- } \\
\text { arms }\end{array}$ & $\begin{array}{l}1.69 \mathrm{~g} \text { total } \\
\text { phenolics/l }\end{array}$ & $\begin{array}{l}30 \text { min treadmill } \\
\text { exercise }(50 \% \\
\left.W_{\max }\right)\end{array}$ & & & $\begin{array}{c}\downarrow \text { TBARS } \\
30 \mathrm{~min} \\
\text { post-ex }\end{array}$ & & & & $\begin{array}{l}\downarrow \text { SBP and } \\
\text { DBP } \\
30 \text { min } \\
\text { post-ex }\end{array}$ & \\
\hline $\begin{array}{l}\text { Trexler } \\
\text { et al. }{ }^{(32)}\end{array}$ & $\begin{array}{l}\text { Nineteen (ten } \\
\text { males, nine } \\
\text { females) } \\
\text { highly active }\end{array}$ & $\begin{array}{c}2 \times 0.5 \mathrm{~g} / \mathrm{d} \\
\text { POMe }\end{array}$ & 30 min pre-ex & $\begin{array}{l}\text { Double-blind, } \\
\text { randomised, } \\
\text { PLA-controlled } \\
\text { crossover (7d } \\
\text { washout) }\end{array}$ & & $\begin{array}{l}\text { Three treadmill runs to } \\
\text { exhaustion at } 90, \\
100 \text { and } 110 \% \text { PV }\end{array}$ & & & & & & & $\begin{array}{l}\uparrow \text { Blood flow } \\
\text { and } \\
\text { vessel } \\
\text { diameters } \\
\text { at } 30 \mathrm{~min} \\
\text { post-ex }\end{array}$ & \\
\hline $\begin{array}{l}\text { Mazani } \\
\text { et al. }\end{array}$ & $\begin{array}{l}\text { Twenty-eight } \\
\text { males } \\
\text { endurance- } \\
\text { athletes }\end{array}$ & 0.24 litre/d POMj & $\begin{array}{l}2 \text { weeks, pre- } \\
\text { ex }\end{array}$ & $\begin{array}{l}\text { Double-blind, } \\
\text { randomised } \\
\text { PLA- } \\
\text { controlled, two- } \\
\text { arms }\end{array}$ & & $\begin{array}{l}\text { Treadmill runs at } 70 \% \\
\max \mathrm{HR}\end{array}$ & & & $\begin{array}{l}\uparrow \text { GPX and } \\
\text { SOD; } \downarrow \\
\text { MDA } \\
\text { post-ex }\end{array}$ & & $\begin{array}{l}\downarrow \text { MMP2, } \\
\text { MMP9, } \\
\text { hs-CRP } \\
\text { post-ex }\end{array}$ & & & \\
\hline $\begin{array}{l}\text { Naghiza- } \\
\text { deh- } \\
\text { Baghi } \\
\text { et al. }{ }^{\left({ }^{36}\right)}\end{array}$ & $\begin{array}{l}\text { Twenty-eight } \\
\text { males } \\
\text { endurance- } \\
\text { athletes }\end{array}$ & 0.24 litre/d POMj & $\begin{array}{l}2 \text { weeks, pre- } \\
\text { ex }\end{array}$ & $\begin{array}{l}\text { Double-blind, } \\
\text { randomised } \\
\text { PLA- } \\
\text { controlled, two- } \\
\text { arms }\end{array}$ & & $\begin{array}{l}\text { Severe based- } \\
\text { endurance activity }\end{array}$ & & & $\begin{array}{c}\uparrow \text { ARE, SOD, } \\
\text { GPX, } \\
\text { TAC; } \downarrow \\
\text { MDA } \\
\text { post-ex }\end{array}$ & & & & & \\
\hline $\begin{array}{l}\text { Fuster- } \\
\text { Munozz } \\
\text { et al. }{ }^{(26)}\end{array}$ & $\begin{array}{l}\text { Twenty } \\
\text { endurance } \\
\text { trained males }\end{array}$ & 0.2 litre/d POMj & $21 \mathrm{~d}$, pre-ex & $\begin{array}{l}\text { Double-blind, } \\
\text { randomised, } \\
\text { PLA- } \\
\text { controlled, } \\
\text { three-arms }\end{array}$ & & $\begin{array}{l}1 \mathrm{~h} / \mathrm{d} \text { based } \\
\text { endurance-training, } \\
\text { three sessions/ } \\
\text { week }\end{array}$ & & $\begin{array}{l}\leftrightarrow \text { ASAT and } \\
\text { ALAT at } \\
\text { day } 22\end{array}$ & & $\begin{array}{l}\downarrow \text { MDA, PC } \\
\text { at day } \\
22\end{array}$ & & $\begin{array}{l}\leftrightarrow \text { sE-selectin } \\
\text { and CRP at } \\
\text { day } 22\end{array}$ & & \\
\hline $\begin{array}{l}\text { Ammar } \\
\text { et al. }{ }^{(18)}\end{array}$ & $\begin{array}{l}\text { Nine elite } \\
\text { weightlifters }\end{array}$ & $\begin{array}{l}0.5 \text { litre } 1 \mathrm{~h} \text { prior } \\
\text { ex+1.5 litres } \\
48 \mathrm{~h} \text { post-ex } \\
(3 \times 0.25 \text { litre/ } \\
\mathrm{d}, 8 \mathrm{~h} \\
\text { interval) }\end{array}$ & $\begin{array}{l}1 \mathrm{~h} \text { pre-ex and } \\
2 \mathrm{~d} \text { post-ex }\end{array}$ & $\begin{array}{l}\text { Double-blind, non } \\
\text { randomised, } \\
\text { PLA-controlled } \\
\text { crossover (48 h } \\
\text { washout) }\end{array}$ & $\begin{array}{l}2.56 \mathrm{~g} / 0.5 \text { litre } \\
\text { POMj }\end{array}$ & $\begin{array}{l}\text { Intense weightlifting } \\
\text { training session }\end{array}$ & $\begin{array}{l}\downarrow \text { CK, } \\
\text { LDH, } \\
\text { ASAT, } \\
\text { at } 3 \text { min } \\
\text { post-ex }\end{array}$ & $\begin{array}{l}\downarrow \mathrm{CK}, \mathrm{LDH}, \\
\text { ASAT at } \\
48 \mathrm{~h} \\
\text { post-ex }\end{array}$ & & & $\begin{array}{l}\downarrow \text { hs-CRP } \\
3 \text { min } \\
\text { post-ex }\end{array}$ & $\begin{array}{l}\leftrightarrow \text { hs-CRP and } \\
\text { leucocytes } \\
\text { at } 48 \mathrm{~h} \text { post- } \\
\text { ex }\end{array}$ & $\begin{array}{l}\downarrow \text { SBP and } \\
\text { HR 3 min } \\
\text { post-ex }\end{array}$ & $\begin{array}{l}\downarrow \mathrm{SBP}, \leftrightarrow \mathrm{HR} \\
\text { at } 48 \mathrm{~h} \\
\text { post-ex }\end{array}$ \\
\hline $\begin{array}{l}\text { Ammar } \\
\text { et al. }{ }^{(19)}\end{array}$ & $\begin{array}{l}\text { Nine elite } \\
\text { weightlifters }\end{array}$ & $\begin{array}{l}0.5 \text { litre } 1 \mathrm{~h} \mathrm{prior} \\
\text { ex }+1.5 \text { litres } \\
48 \mathrm{~h} \text { post-ex } \\
(3 \times 0.25 \text { litre/ } \\
\mathrm{d}, 8 \mathrm{~h} \\
\text { interval })\end{array}$ & $\begin{array}{l}1 \mathrm{~h} \text { pre-ex and } \\
2 \mathrm{~d} \text { post-ex }\end{array}$ & $\begin{array}{l}\text { Double-blind, non } \\
\text { randomised, } \\
\text { PLA-controlled } \\
\text { crossover (48 h } \\
\text { washout) }\end{array}$ & $\begin{array}{l}2.56 \mathrm{~g} / 0.5 \text { litre } \\
\text { POMj }\end{array}$ & $\begin{array}{l}\text { Intense weightlifting } \\
\text { training session }\end{array}$ & & & $\begin{array}{l}\downarrow \text { MDA, } \uparrow \\
\text { GPX, CAT, } \\
\text { UA, Tbil, } \\
\text { at } 3 \text { min } \\
\text { post-ex }\end{array}$ & $\begin{array}{l}\downarrow \mathrm{MDA} \text {, at } \\
\quad 48 \mathrm{~h} \\
\text { post-ex }\end{array}$ & & & & \\
\hline $\begin{array}{l}\text { Roelofs } \\
\text { et al. }\end{array}$ & $\begin{array}{l}\text { Nineteen (eight } \\
\text { males, eleven } \\
\text { females) } \\
\text { recrationally } \\
\text { resistance- } \\
\text { trained }\end{array}$ & $1000 \mathrm{mg}$, POMe & $\begin{array}{c}30 \text { min prior } \\
\text { exercise }\end{array}$ & $\begin{array}{l}\text { Double-blind, } \\
\text { randomised, } \\
\text { PLA-controlled } \\
\text { crossover (7- } \\
10 \mathrm{~d} \text { washout) }\end{array}$ & $3500 \mu \mathrm{mol} / \mathrm{l}$ & $\begin{array}{l}\text { High-intensity } \\
\text { exercises (i.e. RSA, } \\
\text { RTF at } 80 \% \text { on } \\
\text { bench and leg } \\
\text { press) }\end{array}$ & & & & & & & $\begin{array}{c}\uparrow \text { Blood flow } \\
\text { and } \\
\text { vessel } \\
\text { diameters, } \\
\stackrel{\leftrightarrow}{\leftrightarrow} \mathrm{SPO}_{2}, \\
\mathrm{HR} \text { and } \\
\mathrm{BP} \text { at } 0 \\
30 \text { min } \\
\text { post-ex }\end{array}$ & \\
\hline
\end{tabular}




\section{Results}

A total of eleven studies ${ }^{(17-19,25-27,32-36)}$ met the inclusion criteria and were included in the current systematic review. The studies examined either the effects of POM intake on exercise performance and/or exercise-induced fatigue, soreness, muscle damage, oxidative stress, inflammation and cardiovascular function. All studies used a statistical significance threshold of $P<0.05$.

\section{Study selection and characteristics}

Study selection. The predefined search strategies yielded a preliminary pool of 786 possible papers. Removal of duplicates resulted in a selection of 497 published papers. A first screening of titles and abstracts for eligibility against inclusion and exclusion criteria let to a provisional list of sixteen published studies. The full texts of fourteen articles were retrieved, while two studies were excluded because insufficient data were published. After a careful review of the fourteen full texts, three articles were excluded (two studies investigated physical exercises performed in extreme conditions (i.e. altitude, heat) and one study used POM combined with other supplements). Therefore, eleven studies met our inclusion criteria for determining the effects of POM supplementation on exercise performance, recovery and a variety of physiological outcome measurements.

Study characteristics. The characteristics of each study, and the performance and the physiological changes following POM supplementation compared to PLA supplementation, are respectively summarised in Tables 1 and 2. In all, four papers examined the effect of POM supplementation on physical performance and physiological responses, such as muscle damage and inflammation, following strength exercise ${ }^{(18,25)}$; and cardiovascular responses following running ${ }^{(32)}$, cycling ${ }^{(35)}$ and strength $^{(18,35)}$ exercise. In all, two studies only examined the change in physical performance without physiological measurements ${ }^{(17,33)}$, while the remaining five studies only assessed the effect of POM supplementation on the physiological responses to exercise such as muscle damage ${ }^{(26)}$, oxidative stress $^{(19,27,34,36)}$, inflammation ${ }^{(26,27)}$ and cardiovascular function $^{(34)}$. Different exercise models were employed in the studies included in the current systematic review. Specifically, four studies included strength exercises such as unilateral eccen$\operatorname{tric}^{(17,25)}$ and Olympic weightlifting ${ }^{(18,19)}$ movements, three studies employed treadmill running ${ }^{(27,28,34)}$, two studies used a combination of strength and running ${ }^{(33)}$ or cycling ${ }^{(35)}$ exercise, while the two remaining trials used ultra-endurance exercises $^{(26,36)}$. Further measures completed to assess the physiological effects of POM supplementation included $\mathrm{RPE}^{(18)}$, perceptions of $\operatorname{DOMS}^{(17,18,25)}$ and pain and vitality scales ${ }^{(28)}$, which are presented with performance in Table 1 . Concerning the acute (up to $2 \mathrm{~h}$ ) and delayed (at least $24 / 48 \mathrm{~h}$ ) responses to exercise, four studies assessed the acute and delayed performance and/or physiological responses ${ }^{(17-19,25)}$, five studies only assessed the acute responses ${ }^{(27,32,34-36)}$, while two studies ${ }^{(26,33)}$ only assessed the delayed responses.
Subjects characteristics. The studies involved in this systematic review included a total of 230 participants (190 males, twenty females, with twenty not specified). The number of participants in each trial ranged from $9^{(18,19)}$ to $45^{(37)}$, with a mean sample size of 20.9 (SD 10) and a mean age ranging from $21^{(17-19)}$ to $35^{(26)}$ years. These eleven studies targeted healthy adult participants of varying fitness status. In all, four studies recruited recreationally- ${ }^{(25,33,34)}$ to highly- ${ }^{(32)}$ active participants (total $n 100$ participants), four studies ${ }^{(17-19,35)}$ recruited resistance trained participants ( $n 54$ participants) and three studies ${ }^{(26,27,36)}$ recruited endurance trained athletes (total $n$ 74).

Study design and supplement administration. As presented in Tables 1 and 2, the reviewed studies (nine out of eleven) implemented a double-blind, PLA-controlled experimental design. The majority of these studies (nine out of eleven) employed a randomised design where (i) two studies employed three experimental arms ${ }^{(26,33)}$ with at least one being POM treatment, (ii) three studies used two experimental arms ${ }^{(27,34,36)}$ and (iii) four studies used one experimental arm (i.e. crossover design) with a 1 week $^{(32,35)}$ or a 2 week washout period ${ }^{(17,25)}$. Concerning, the two remaining studies ${ }^{(18,19)}$, the experimental protocol was completed during 1 week of an intensive training program in a group of elite weightlifters (i.e. one experimental arm) which necessitated a small washout period ( $48 \mathrm{~h})$. Therefore, to avoid any possible protracted effect of POM supplementation on the physiological responses post training, the authors selected a non-randomised crossover design with the POM treatment administered first for all participants. The eleven trials included in this review employed one of two varieties of dietary POM supplementation with an intervention period that ranged from $30 \mathrm{~min}$ to $21 \mathrm{~d}$. The majority $(n 9)$ opted for POMj, with beverages ingested both before and following the training/exercises sessions. Indeed, in five studies, participants were supplemented for $4 \mathrm{~d}$ pre- and $4 / 5 \mathrm{~d}$ post-exercise with 0.5 litre POMj once or twice daily ${ }^{(25,33)} ; 7 \mathrm{~d}$ pre- and $8 \mathrm{~d}$ post-exercise with 0.25 litre twice daily ${ }^{(17)} ; 1 \mathrm{~h}(0.5$ litre) preand $2 \mathrm{~d}(3 \times 0.25$ litre/d $)$ post exercise ${ }^{(18,19)}$. In the remaining four studies, POM was only ingested before exercises sessions with a treatment of: 0.5 litre/d during a period of 1 week $^{(34)}$; 0.24 litre/d during a period of 2 weeks ${ }^{(27,36)}$; or $0 \cdot 2$ litre/d during a period of 3 weeks ${ }^{(26)}$. The two remaining studies ${ }^{(32,35)}$ opted for an acute consumption of $1000 \mathrm{mg}$ POMe $30 \mathrm{~min}$ before exercises sessions. With regard to the antioxidant capacity of the POM supplements administered in the selected studies, the total phenolic content ranged from $0.65 \mathrm{~g} / 0.5$ litre $^{(17,25,33)}$ to $2.56 \mathrm{~g} / 0.5$ litre $^{(18,19)}$.

Methodological quality of studies. All reviewed studies scored a moderate to high score of 7 and above with a mean PEDro score of 8.9 (SD 0.9). Of the eleven studies included, three investigations ${ }^{(17,25,35)}$ received a perfect score of 10 , five investigations $^{(18,19,32-34)}$ scored 9 out of 10 as they failed to randomly allocate subjects to a group or failed to achieve similar baseline values for the primary outcome measure, two investigations ${ }^{(26,27)}$ scored 8 out of 10 as they failed to blind 
therapists and achieve similar baseline values for the primary outcome measure, and the remaining investigation ${ }^{(36)}$ scored 7 out of 10 as the authors failed to achieve similar baseline values for the primary outcome measure and to blind the experimenters to the supplement order. Overall, the study quality was deemed to be good to excellent.

\section{Effect of pomegranate on acute and delayed physical performance}

A total of six studies assessed the effect of POM supplementation on exercise performance $e^{(17,18,25,32,33,35)}$. In all, three of these studies evaluated the change in acute (i.e. immediately and up to $2 \mathrm{~h}$ ) physical performance after treadmill ${ }^{(32)}$, repeated sprint ability (RSA) ${ }^{(35)}$ and strength ${ }^{(18,35)}$ exercise with the remaining three studies assessing the delayed (i.e. after a period of at least $24 / 48 \mathrm{~h}$ following exercise) effect of POM on strength recovery following unilateral ${ }^{(17,25)}$ and bilateral eccentric exercise $^{(33)}$.

Effect on acute physical performance. In highly active participants, ingestion of $1000 \mathrm{mg}$ of POMe $(2 \times 500 \mathrm{mg}$ capsules $)$ 30 min before exercise (Table 1) was reported to improve time to exhaustion during treadmill running at $90 \%$ (388 (SD 199) $v$. 346 (sD 163) s) and $100 \%$ (171 (sD 66) v. 159 (sD 62) s) but not $110 \%$ (108 (SD 45) v. 104 (SD 40) s) of the peak velocity (PV) obtained in a graded treadmill test continued until exhaustion $^{(32)}$. Moreover, the average and peak power output in sprint 5 during an RSA test on a friction-braked cycle ergometer (i.e. $6 \mathrm{~s}$ maximal sprints $\times$ ten repetitions with a load of $65 \mathrm{~g} / \mathrm{kg}$ of body mass applied and a $30 \mathrm{~s}$ passive recovery separating intervals) was also enhanced following the same POMe ingestion procedures ${ }^{(35)}$. With regard to resistance exercise performance, POMe ingestion has been reported to have no effect on the number of repetitions to fatigue (RTF) during bench and leg press exercise ${ }^{(35)}$. Conversely, Ammar et al. ${ }^{(18)}$ recently showed that consumption of $500 \mathrm{ml}$ POMj $60 \mathrm{~min}$ before high-intensity weightlifting exercise enhanced the total $(8.3 \%)$ and maximal (3.26\%) load lifted in two Olympic movements (snatch and clean and jerk) compared to the PLA condition (Table 1). The discrepancies between studies could be linked to inter-study differences in the supplementation procedures employed. Therefore, the existing findings suggest that ingestion of $500 \mathrm{ml}$ of $\mathrm{POMj} 60 \mathrm{~min}$ before exercise is more likely to enhance resistance exercise performance than $1000 \mathrm{mg}$ of POMe ingested $30 \mathrm{~min}$ before exercise.

The enhanced performance following POM ingestion might be linked to increased muscle BF. Indeed, Trexler et al. ${ }^{(32)}$ observed enhanced performance in association with an increase in post exercise VD and brachial artery BF after POMe ingestion. However, given that $\mathrm{BF}$ was only investigated postexercise at the brachial artery in this study, it still unclear whether POM increases arm and/or leg BF during exercise. The beneficial effect of POM on BF could be due to its high content of polyphenols (e.g. flavonoids) which can promote nitric oxide (NO) synthesis (an important contributor to exercise-induced vasodilation $^{(37)}$ by enhancing NO synthase activity, and NO bioavailability, through limiting $\mathrm{NO}$ scavenging by reactive oxygen species $(\mathrm{ROS})^{(38)}$.

Effects of pomegranate on muscle strength recovery. The performance of eccentric exercise has been shown to reduce maximal strength and increase the sensation of soreness in the exercising muscles, with muscle soreness peaking $24-48 \mathrm{~h}$ post such exercise $\mathrm{e}^{(39)}$. Although, soreness scores return towards baseline after this point ${ }^{(40)}$, strength can remain depressed compared to baseline even up to several days after undertaking eccentric exercise ${ }^{(41)}$. It has been reported that full recovery of strength typically requires $7-14 \mathrm{~d}^{(42)}$. To date, studies assessing the effect of POM supplementation on post exercise muscle recovery (Table 1 ) have shown that, in both untrained ${ }^{(25)}$ and trained $^{(17)}$ subjects, consumption of $500 \mathrm{ml}$ POMj for 9-15 d before an intensified training session (two to three sets of twenty unilateral maximal eccentric elbow flexion) can expedite the recovery of strength assessed during the $2-168 \mathrm{~h}$ period post exercise. Indeed, compared to PLA, there was greater strength recovery following POMj supplementation at $48 \mathrm{~h}$ ( $85 v .78 \%$ ) and $72 \mathrm{~h}(89 v .84 \%)$ post exercise ${ }^{(25)}$. Concerning the effect of POMj supplementation on lower limb recovery, Trombold et al. ${ }^{(17)}$ showed that the recovery of knee extensor isometric strength was not affected by POMj after six sets of ten unilateral eccentric knee extension exercise performed by resistance trained men. Collectively, these initial studies suggested that POM supplementation can accelerate strength recovery in arm muscles but not leg muscles. More recently, however, Machin et al. ${ }^{(33)}$ showed that consuming POMj either once-daily $(650 \mathrm{mg} / \mathrm{d})$ or twice-daily $(1300 \mathrm{mg} / \mathrm{d})$ improved strength recovery in both leg and arm muscles after completing unaccustomed eccentric exercise in recreationally active men (Table 1). These conflicting results could be explained by the training status of the participants (untrained $v$. resistance trained subjects) and/or the composition of the eccentric exercise protocols. Specifically, the eccentric exercise protocol employed by Machin et al. ${ }^{(33)}$ was based on 20 min of downhill running, thereby engaging both sets of leg muscles and provoking a greater degree of physiological perturbation ${ }^{(43)}$, whereas Trombold et $a l .{ }^{(17)}$ used a protocol comprising six sets of ten eccentric unilateral knee extension exercises. The beneficial effect of POM on muscle strength recovery has recently been related to its antioxidant and anti-inflammatory properties $^{(18,19)}$ and its ability to enhance vasodilation and $\mathrm{BF}^{(32,37)}$

\section{Effect of pomegranate on muscle fatigue, pain and soreness}

A total of four studies have examined the effects of POM on muscle fatigue, pain and soreness following physical exercise $e^{(17,18,25,32)}$. In all, three of these studies analysed the change in muscle fatigue and soreness acutely and up to $48 \mathrm{~h}^{(18)}$ or $96 h^{(17,25)}$ post strength exercise, while only one study focused on the effect of POM on muscle pain immediately following treadmill runs session ${ }^{(32)}$. 
Effect on acute muscle fatigue, pain and soreness. In untrained subjects (Table 1 ), a daily drink of POMj before ( $4 \mathrm{~d}$ ) and following $(4 \mathrm{~d})$ intense upper body eccentric exercise has been reported to lower the perception of muscle soreness in the elbow-flexors $120 \mathrm{~min}$ post-exercise ${ }^{(25)}$. Similarly, POMj consumed $1 \mathrm{~h}$ before and over the $48 \mathrm{~h}$ following a resistance training session (Table 1) has been reported to blunt the acute perception of muscle fatigue with lower ratings of perceived exertion (RPE) values reported (-4.37\%) following POMj supplementation $^{(18)}$. The immediate lowering of post-exercise muscle fatigue and soreness following POMj supplementation might be explained by blunted tissue oedema and/or a lower accumulation of metabolic by-products which relay information to the central nervous system via groups III and IV muscle afferents $^{(44)}$. This reduction in muscle soreness and fatigue following POMj supplementation might be expected to translate into less fatigue in a subsequent training session, which may have implications for enhancing physical performance during a training programme ${ }^{(22,24)}$. With regard to the effect of POM supplementation on the perception of muscle soreness and fatigue following intermittent exercise, it has been reported that pain, as assessed using the visual analogue pain scale, was not significantly affected by POMe treatment ${ }^{(32)}$. However, the following statement on the vitality scale, 'At this moment I feel alive and vital', was found to be greater $30 \mathrm{~min}$ following POMe ingestion $^{(32)}$. Taken together, these results indicate that POM supplementation appears to acutely attenuate the sensation of fatigue and soreness post exercise with potential implications for performance in subsequent training sessions.

Effect on delayed onset muscle soreness. Exhaustive or unaccustomed intense exercise can cause muscle damage, which results in pain, tenderness, swelling and stiffness. Given the delayed nature of these symptoms, they are collectively referred to as DOMS ${ }^{(45)}$. Trombold et al. ${ }^{(17,25)}$ were the first to assess the effect of POMj supplementation on the DOMS provoked by a bout of intense eccentric exercise (Table 1). These studies showed that consumption of $250-500 \mathrm{ml}$ POMj twice daily could attenuate elbow-flexor muscle soreness at 48 and $72 \mathrm{~h}$ post exercise in resistance trained males ${ }^{(17)}$, but not in recreationally active males ${ }^{(25)}$. However, knee extensor muscle soreness was not significantly affected by POMj in either population $^{(17)}$. Therefore, in response to unilateral eccentric exercise, these authors concluded that POMj supplementation can alleviate exercise-induced soreness of the arm muscles, but not leg muscles, with this beneficial effect more likely to occur in resistance training individuals. Conversely, POMj supplementation has been reported to lower the perception of muscle soreness (i.e. at $48 \mathrm{~h}$ ) in knee extensors, but not the elbow flexors, in elite weightlifters completing whole body resistance exercise $^{(18)}$. The authors of this study ascribed the absence of a lower soreness perception in elbow flexors after POMj supplementation to the lower soreness provoked by the weightlifting exercises in the arms compared to the legs. Accordingly, the lower muscle pain in the upper compared to the lower body musculature likely lowered the scope for a POMj-mediated attenuation in muscle soreness in the former compared to the latter. Therefore, it appears that the blunting of muscle soreness post POMj supplementation might be linked to the degree of soreness evoked by a given exercise task.

In addition to inter-study differences in limb-specific muscle soreness responses post POMj supplementation, the studies of Ammar et $a l .{ }^{(18)}$ and Trombold et al. ${ }^{(17)}$ yielded contrasting results on the effects of POMj on muscle soreness of the same muscle group (knee extensors) in response to whole body ${ }^{(18)}$ or unilateral $^{(17)}$ resistance exercise. The blunting in knee extensor muscle soreness in the study by Ammar et al. ${ }^{(18)}$, but not Trombold et al. ${ }^{(17)}$, might be linked to the higher polyphenol content of the POMj administered by Ammar et al. ${ }^{(18)}(2.56 \mathrm{~g} /$ $500 \mathrm{ml} \mathrm{v}$. $650 \mathrm{mg} / 480 \mathrm{ml}$, respectively). Alternatively, or in conjunction with the different polyphenol doses administered, the disparate effects of POMj supplementation in these studies could be a function of differences the muscle mass engaged (large muscle mass exercise $v$. one limb knee extensor) or the exercise tasks completed (combination of eccentric and concentric $v$. eccentric only exercises) in Ammar et al. ${ }^{(18)}$ compared to Trombold et al. ${ }^{(17)}$, respectively. Therefore, the potential for POM supplementation to blunt muscle soreness appears to be positively related to the dose of polyphenols administered and the volume of muscle mass engaged. Thus, dietary supplementation with POM containing a sufficient dose of polyphenols could be an effective treatment to improve the recovery of muscles strength and weakness which might result in a lower fatigue perception and higher performance in the subsequent training session ${ }^{(22,24)}$.

\section{Effect of pomegranate supplementation on muscle damage responses}

The mechanisms that underpin muscle damage are believed to involve both mechanical and metabolic processes ${ }^{(46)}$. Since, mechanical and metabolic demands on the skeletal muscles are influenced by the nature of physical activity, it was suggested that the magnitude and the level of muscle damage are affected by the mode, intensity and duration of exercise ${ }^{(47)}$. To date, two general phases have been proposed to describe the damage responses during and following physical exercise. The first phase is initiated during exercise and involves mechanical and metabolic responses which are collectively referred to as primary or acute damage ${ }^{(47)}$, while the second phase is associated with an ensuing inflammatory response which develops following exercise (i.e. days to weeks) and is termed delayed damage $^{(48)}$. Of the eleven studies conducted to date, three studies have investigated the effect of POM supplementation on exercise-induced muscle damage with two studies assessing both acute ( $3 \mathrm{~min}$ to $2 \mathrm{~h}$ ) and delayed (1-4 d) responses to strength exercises ${ }^{(18,25)}$ and one study assessing only the delayed effect of POM following an endurance training $\operatorname{session}^{(26)}$.

Effect on acute muscle damage responses. In recreationallyactive males (Table 2) Trombold et al. ${ }^{(25)}$ showed that, compared to PLA, POMe supplementation had no effect on muscle damage markers $2 \mathrm{~h}$ post unilateral eccentric exercise. Indeed, 
in response to two sets of twenty maximal eccentric elbow flexion repetitions, CK was increased to a similar extent in both the PLA and POMe conditions with no change in $\mathrm{Mb} 2 \mathrm{~h}$ post exercise. In contrast, using Olympic weightlifting exercises (Table 2), Ammar et al. ${ }^{(18)}$ reported a blunting in muscle damage following whole body resistance exercise in welltrained subjects after POMj supplementation. Specifically, consumption of POMj attenuated the acute increase of CK $(-8.75 \%)$ and $\mathrm{LDH}(-1.64 \%)$, and blunted the increase of ASAT and alkaline phosphatase compared to the PLA condition. Similar to the muscle soreness results, these conflicting results could: (i) be explained by the lower volume of muscle mass engaged, and by extension experiencing damage, in the study of Trombold et al. ${ }^{(25)}$, (ii) confirm that the magnitude of muscle damage responses (and therefore scope for recovery) are affected by the nature of exercise ${ }^{(47)}$ and (iii) reflect an attenuated acute beneficial effect of POM on muscle damage following unilateral exercise.

Effect on delayed muscle damage responses. Similar to the results observed $2 \mathrm{~h}$ post exercise, Trombold et $a l^{(25)}$ did not observe a beneficial effect of POMj on the delayed damage responses 1-4 d following eccentric unilateral elbow exercise. Indeed at 24, 72 and $96 \mathrm{~h}$ post-exercise, no differences in CK and $\mathrm{Mb}$ were observed in untrained subjects between the POMe and PLA conditions. These findings were corroborated in trained endurance athletes by Fuster-Muñoz et al. ${ }^{(26)}$ who showed that consumption of $200 \mathrm{ml}$ of POMj did not affect ASAT and alanine aminotransferase (ALAT) responses during a 3 week training program (Table 2 ). The authors concluded that the 3 week intervention was not sufficient to elicit a blunting in ASAT and ALAT in trained endurance athletes after POMj supplementation and suggested that an extended supplementation period (i.e. intervention period $>3$ weeks) could result in significant differences between the POMj and PLA groups ${ }^{(26)}$. However, POMj supplementation had a different effect in welltrained resistance subjects ${ }^{(18)}$. Indeed, the consumption of POMj $48 \mathrm{~h}$ before and during the training session accelerated muscle damage recovery $48 \mathrm{~h}$ post a weightlifting training session by expediting the recovery kinetics of CK (11.43\%), LDH $(5.08 \%)$ and ASAT (4.94\%). These results indicated that $48 \mathrm{~h}$ POMj supplementation can be sufficient to restore muscle damage to baseline levels following an intense strength training session (Table 2). Therefore, a natural POMj with high polyphenol concentration (i.e. $2 \cdot 56 \mathrm{~g} / 500 \mathrm{ml}$ ) could be a practical and potent treatment to alleviate muscle damage following intense physical exercise, particularly in resistance training individuals

\section{Effect of pomegranate supplementation on oxidative stress responses}

Oxidative stress reflects an imbalance between pro-oxidant and antioxidant status with the former outweighing the latter ${ }^{(49)}$. Strenuous exercise or intensified training has been shown to elicit acute oxidative stress during exercise and to exhibit a delayed recovery of oxidative stress biomarkers (lipid peroxidation and enzymatic antioxidant) following exercise cessation $^{(50)}$. It is well accepted that exercise provokes the development of oxidative stress by enhancing ROS production via increased phospholipase A2, NADPH oxidase and xanthine oxidase activities $^{(50)}$. It is recognised that increased ROS exposure can contribute to fatigue during exercise via the oxidation of critical redox-sensitive sites within skeletal muscle ${ }^{(50)}$ and the resulting structural damage to lipids, protein and DNA oxidation. However, recent evidence suggests that ROS are also integral to the adaptive responses of muscle fibres to exercise stress via the activation of transcription pathways that regulate gene and protein expression within skeletal muscle ${ }^{(50)}$. Despite the high antioxidant capacity of POM (i.e. rich in polyphenols such as anthocyanins, flavonols and certain ellagitannins such as punicalagin ${ }^{(51)}$ and its resultant potential to mitigate exerciseinduced oxidative stress, few studies ( $n$ 5) have assessed the effects of POM on post-exercise oxidative stress ${ }^{(19,26,27,34,36)}$.

Effect on acute oxidative stress responses. To date, four studies have examined the effect of POM supplementation on oxidative stress biomarkers immediately following physical exercise $^{(19,27,34,36)}$. Specifically, these studies aimed to evaluate the efficacy of POMj consumption to improve the immediate antioxidant responses to exhaustive exercise in young healthy males $^{(27,34,36)}$ and in elite weightlifters ${ }^{(19)}$. Mazani et al. ${ }^{(27)}$, Naghizadeh-Baghi et al. ${ }^{(36)}$ and Ammar et al. ${ }^{(19)}$ reported that consumption of POMj before exercise $\left(240 \mathrm{ml} / \mathrm{d}\right.$ for $14 \mathrm{~d}^{(27,36)}$ and $750 \mathrm{ml} / \mathrm{d}$ for $2 \mathrm{~d}^{(19)}$ enhanced the activity of key antioxidant enzymes and attenuated lipid peroxidation immediately after treadmill running ( $70 \%$ maximal $\mathrm{HR}$ ), ultra-endurance exercise and a weightlifting training session. While lipid peroxidation markers and the activity of enzymatic antioxidants were increased at post exercise in both the POMj and PLA groups, the pre-post exercise change was higher for enzymatic (e.g. SOD, GPX and CAT) and non-enzymatic antioxidants (e.g. UA and total bilirubin) and lower for MDA in the POMj condition compared to the PLA condition ${ }^{(19,27,36)}$. These observations support the use of $\mathrm{POMj}$ consumption to enhance antioxidant status in humans completing intense exercise ${ }^{(52)}$. Indeed, these findings are consistent with those of Tsang et al. ${ }^{(34)}$ who showed that 1 week of POMj consumption $(500 \mathrm{ml} / \mathrm{d}$ containing $1.69 \mathrm{~g}$ total phenolics/l) significantly lowered urinary lipid peroxidation levels in the POMj group immediately after $30 \mathrm{~min}$ of treadmill running $\left(50 \% W_{\max }\right)$. Consistent with these findings, previous studies in sedentary subjects reported the effectiveness of POMj supplementation to neutralise $\operatorname{ROS}^{(53,54)}$. Collectively, the existing literature suggests that POMj supplementation has the potential to blunt exercise-induced oxidative stress.

Effect on delayed oxidative stress responses. The effect of $\mathrm{POMj}$ consumption on the delayed oxidative stress response following exercise has only been investigated in the studies of Fuster-Muñoz et al. ${ }^{(26)}$ and Ammar et al. ${ }^{(19)}$, which recruited adult endurance and resistance trained males, respectively. In endurance trained males, $22 \mathrm{~d}$ of POMj supplementation attenuated PC and MDA levels such that these biomarkers were only increased following endurance training sessions in the PLA 
group $(1.1 v \cdot 1.8 \mathrm{nmol} / \mathrm{mg}$ and $14.1 v \cdot 10 \cdot 9 \mathrm{nmol} / \mathrm{g}$ protein, respectively for $\mathrm{PC}$ and MDA), suggestive of a reduction in oxidative stress during the aerobic training session after POMj supplementation $^{(26)}$. Similarly, resistance trained males exhibited a delayed effect of POMj in response to a weightlifting training session. Indeed, $48 \mathrm{~h}$ following a resistance exercise session, Ammar et al. ${ }^{(19)}$ reported expedited recovery kinetics of MDA (5.63\%) and the antioxidant enzymes, CAT (8.94\%) and GPX (10.21\%) markers with POMj compared to PLA supplementation. Therefore, POMj supplementation appears to be effective at blunting oxidative stress biomarkers following both endurance and resistance exercise sessions. Consistent with these findings, previous studies in healthy non-active subjects showed that $15 \mathrm{~d}$ of POMj consumption increased levels of GSH (22.6\%) and lowered levels of MDA (24.4\%) and PC (17.7\%) even 1 week after POMj administration has terminated ${ }^{(52)}$. Collectively, the existing literature suggests that, even after ceasing POMj consumption, some of its beneficial effects on antioxidant status prevail for at least a few days. Although the mechanisms for these delayed effects have not been resolved, they might be linked to a protracted radical scavenging, antioxidant recycling and modulation of antioxidant enzymatic activity ${ }^{(55)}$.

\section{Effect of pomegranate supplementation on inflammatory responses}

Intense physical exercise, has been shown provoke a rapid and pronounced local inflammatory response (i.e. invasion of muscle by inflammatory cells). Thereafter, a systemic inflammatory response, known as acute-phase response ${ }^{(56)}$, becomes manifest that can persist for days to weeks ${ }^{(49)}$. The leucocytes are the major cellular mediators of inflammation ${ }^{(57)}$. The increased prevalence of leucocytes after intense exercise ${ }^{(58)}$ is believed to be mainly due to the rise of neutrophils and monocyte/macrophage influx as determined by the expression of leucocyte adhesion molecules ${ }^{(57)}$. In addition, the secretion of pro-inflammatory cytokines, such as TNF- $\alpha$ and IL- $1 \beta$, and the inflammation responsive cytokine, IL- 6 , by the endothelial cells is believed to mediate exercise-induced inflammatory process $^{(56)}$. Moreover, during physically demanding exercise tasks, hs-CRP, ceruloplasmin and MMP have previously been classified as biomarkers of inflammation. Indeed, the contraction of skeletal muscle after intense physical activity has been shown to stimulate the local production of $\mathrm{MMP}^{(59)}$, which play a physiological role in muscle regeneration ${ }^{(60)}$ and adaptation $^{(61)}$ to exercise training. Of the several MMP, previous studies have shown that MMP2 (gelatinase A) and MMP9 (gelatinase B) play critical roles in remodelling and regenerating skeletal muscle following exercise ${ }^{(62)}$. Therefore, in this section we will focus on the main results of studies $(n 4)$ which have investigated the effect of $\mathrm{POMj}$ supplementation on the acute $^{(18,25,27)}$ and delayed ${ }^{(18,25,26)}$ responses of inflammatory markers (i.e. leucocytes, IL, CRP or hs-CRP, MM2 and MM9) following intensive exercises (Table 2).

Effect on acute inflammatory responses. In untrained subjects, Trombold et al. ${ }^{(25)}$ observed no change in IL-6 and hs-CRP responses in either the PLA or POMj group immediately following exercise. In this study, the absence of inflammatory responses following unilateral eccentric exercise could be explained by the small volume of muscle mass recruited. Indeed, when a similar type of exercise has been completed with a larger muscle mass recruited, previous studies have found increases in systemic IL-6 and hs-CRP ${ }^{(63)}$ and local inflammation ${ }^{(64)}$ post exercise. Consistent with this interpretation, Mazani et $a l^{(27)}$ showed a significant increase in inflammatory markers following exhaustive running exercise with higher pre- to post-exercise changes in MMP2, MMP9 and hs-CRP in the PLA group compared to a group receiving $14 \mathrm{~d}$ of $\mathrm{POMj}$ supplementation. These results indicate that regular intake of POMj before exercise significantly blunts inflammatory responses before and after exhaustive exercise. The acute anti-inflammatory effect of POMj observed in sedentary subjects in the study of Mazani et al. ${ }^{(27)}$ has been recently confirmed by Ammar et al. ${ }^{(18)}$ using resistance trained subjects. Indeed, the consumption of POMj during the $48 \mathrm{~h}(1500 \mathrm{ml})$ and the last $1 \mathrm{~h}(500 \mathrm{ml})$ before a weightlifting training session, which recruited a large muscle mass, was found to attenuate the increase in hs-CRP post exercise. Collectively, these findings support the anti-inflammatory properties of polyphenol-rich POMj supplementation previously reported in sedentary healthy subjects and patient populations ${ }^{(\mathcal{9}, 14,15,62)}$ and suggest that the beneficial effect of POM is influenced by the volume of skeletal muscle mass recruited during exercise. Although the underlying mechanisms of the anti-inflammatory effects of POM supplementation are not entirely clear, various explanations have been proposed. For example, Ammar et al. ${ }^{(18)}$ suggested that the lower post-exercise level of hs-CRP following POMj supplementation could be due to the inhibition of some inflammatory markers such as NF- $\kappa \mathrm{B}, \mathrm{TNF}-\alpha$ and COX-2. In addition, given that the inhibition of MMP by TNF has been reported to be dependent on reducing ROS production ${ }^{(65)}$, and since polyphenoliccompounds present in POM have been shown to confer antioxidant properties that inhibit ROS production ${ }^{(53)}$, blunted ROS production following POM supplementation might contribute to its anti-inflammatory effects ${ }^{(27)}$.

Effect on delayed inflammatory responses. In endurance trained athletes, Fuster-Muñoz et al. ${ }^{(26)}$ reported that the levels of sE-selectin and hs-CRP over $22 \mathrm{~d}$ following aerobic training sessions was not measurably impacted by the consumption of POMj. Similarly, in resistance trained athletes, Ammar et al. ${ }^{(18)}$ observed no effect of POMj on the recovery kinetics of hs-CRP and leucocyte levels $48 \mathrm{~h}$ following a weightlifting training session. However, given that hs-CRP better reflects endothelial dysfunction and vascular inflammation than muscular function $^{(26)}$, future studies would benefit from evaluating the effect of POM supplementation on the profiles of cytokines such as TNF or IL-6 which better relate to exercise performance ${ }^{(66)}$.

\section{Effect of pomegranate juice/pomegranate extract on cardiovascular parameters}

It is well established that the demand for oxygen and metabolic substrates increases in the contracting skeletal muscles during 
physical exercise. To meet these elevated demands, BF to working musculature is increased during exercise ${ }^{(37)}$. NO production has been shown to be an import contributor to exercise-induced skeletal muscle hyperaemia ${ }^{(67)}$. Polyphenols have also been reported to improve cardiovascular function during stressful situations ${ }^{(68,69)}$. Given that polyphenol-rich $\mathrm{POMj}$ has been reported to protect $\mathrm{NO}$ from oxidative scavenging and to enhance the biological actions of $\mathrm{NO}^{(38)}$, the beneficial effect of POMj supplementation on cardiovascular function might be NO-mediated. Although previous studies have investigated the effect of POM supplementation on HR, $\mathrm{BF}$, vessel dilation and cardiovascular function in sedentary subjects $^{(6,7,12,53,67)}$, a limited numbers of studies have investigated the effect of POM supplementation on these parameters during exercise and to what extent this might contribute to a potential ergogenic effects of POM supplementation. This section will focus on the main findings of studies $(n$ 4) that have investigated how the consumption of POM impacts cardiovascular responses immediately ${ }^{(18,32,34,35)}$ and up to $48 \mathrm{~h}^{(18)}$ following running or strength exercise (Table 2).

Effect on acute cardiovascular responses. To date, two studies have investigated the effect of POM on BF and VD responses immediately following physical exercise ${ }^{(28,35)}$. In these studies the consumption of $1000 \mathrm{mg}$ of POMe $(2 \times 500 \mathrm{mg}$ capsules) $30 \mathrm{~min}$ before exercise was reported to increase VD and BF immediately, and up to $30 \mathrm{~min}$, after exhaustive exercise compared to a PLA condition. Indeed, POMe supplementation has been reported to result in a larger VD (0.42(SD 0.07) $v$. $0 \cdot 39(\mathrm{sD} 0.07) \mathrm{cm}$ ) and higher $\mathrm{BF}(40.6(\mathrm{sD} 24.8) v .29 \cdot 6(\mathrm{SD} 24.9)$ $\mathrm{ml} / \mathrm{min}) 30 \mathrm{~min}$ post-POMe ingestion and $30 \mathrm{~min}$ post three treadmill runs to exhaustion (at 90, 100 and $110 \% \mathrm{PV})^{(28)}$. Similarly, POMe ingestion lead to a larger VD immediately following leg press and bench press exercise at $80 \%$ one repetition maximum ( 1 RM) continued to fatigue (mean difference $=0.042 \mathrm{~cm}$ for leg press and $0.029 \mathrm{~cm}$ for bench press) and $30 \mathrm{~min}$ post-leg press (mean difference $=0 \cdot 029)^{(35)}$. This beneficial effect of POMe was also observed following a RSA test with higher BF and VD observed respectively immediately and $30 \mathrm{~min}$ post exercise following POMe ingestion ${ }^{(35)}$. Given that NO production is an important contributor to vasodilatation $^{(37)}$, and that polyphenols have been shown to phosphorylate and thereby activate endothelial NO synthase ${ }^{(38,70)}$, the results of Roelofs et al. ${ }^{(35)}$ could be explained by the high content of polyphenols in the POMe supplement $(3500 \mu \mathrm{mol} / \mathrm{l})$. Moreover, the protective role of POM against ROS-mediated NO scavenging ${ }^{(38)}$ could also explain the enhanced vasodilation following exercise.

Assuming POM supplementation increases BF during exercise, the associated increase in nutrient delivery to, and efflux of noxious metabolic by-products from, skeletal muscle ${ }^{(37,67)}$ might contribute to ergogenic effect of POM supplementation during exercise and the enhanced post-exercise recovery $^{(17,18,25,32)}$. In addition to effects on $\mathrm{BF}$ and $\mathrm{VD}^{(32,35)}$, POM has been reported to lower blood pressure and HR during physical exercise ${ }^{(18,34)}$. Indeed, daily consumption of $\mathrm{POMj}$ $\left(500 \mathrm{ml}, 1.69 \mathrm{~g}\right.$ total phenolic/l) for 1 week before exercise ${ }^{(34)}$ was shown to lower the SBP and the diastolic blood pressure (DBP) before and immediately after $30 \mathrm{~min}$ of treadmill exercise $\left(50 \% W_{\max }\right)$. Likewise, the consumption of POMj $(500 \mathrm{ml}) 1 \mathrm{~h}$ before the training session was shown to attenuate the acute increase of SBP $(-4.46 \%)$ and HR $(-1.81 \%)$ immediately (i.e. $3 \mathrm{~min}$ ) after intense weightlifting exercise ${ }^{(18)}$. The reduction in post-exercise blood pressure and $\mathrm{HR}$ with $\mathrm{POMj}$, if also observed during exercise, implies that POMj supplementation might improve performance and lower the perception of fatigue $^{(17,18,25)}$ by improving aspects of cardiovascular function.

Effect on delayed cardiovascular responses. The effect of $\mathrm{POM}$ on the delayed recovery of cardiovascular responses following exercise is currently unclear. Indeed, only one study has examined SBP and HR responses $48 \mathrm{~h}$ post exercise after POMj supplementation $^{(18)}$. To our knowledge, the delayed responses of $\mathrm{BF}, \mathrm{VD}$ and $\mathrm{DBP}$ have yet to be assessed. The consumption of POMj before an intensive weightlifting training session improved the recovery kinetics of SBP $48 \mathrm{~h}$ post-exercise in elite weightlifters $^{(18)}$. Given that the reduction of SBP following POMj has been linked to a reduction in the cortisol:cortisone ratio $^{(34)}$, the beneficial effect of POMj on SBP during exercise could be the result of $11 \beta$-hydroxysteroid dehydrogenase type 1 inhibition ${ }^{(34)}$. However, further studies are necessary to resolve the mechanisms for the improved cardiovascular function following POM supplementation.

\section{Discussion}

This systematic review evaluated the existing literature assessing the effect of POM supplementation on physical performance, muscle soreness and physiological responses during and following different exercise sessions. Based on the studies assessed in this review, POM supplementation appears to hold potential as a nutritional aid to enhance performance during endurance $^{(28,35)}$ and strength ${ }^{(17,18,25,33)}$ exercise, and to expedite enhanced post exercise recovery of skeletal muscle function $^{(17,25,33)}$. These improvements in exercise performance and recovery have been linked to an attenuation of muscle damage $^{(18)}$; lowered oxidative stress ${ }^{(19,26,27,34,36)}$ and inflammation $^{(18,27)}$; and enhanced cardiovascular function ${ }^{(18,28,34,36)}$. This review has potential implications for improving the use of POM supplementation by athletes, nutritionists and coaches to enhance exercise performance and post-exercise recovery.

Dietary supplementation with POM has shown promising potential to enhance physiological responses in sedentary individuals and patient populations under conditions of physiological strain ${ }^{(7-11)}$. Since physical exercise is a potent and multifaceted physiological stressor, as evidenced by an increase in muscle damage, oxidative stress, inflammation and cardiovascular strain $^{(20-25)}$, a number of recent studies have examined the potential for POM supplementation to enhance exercise performance and post exercise recovery. When the existing literature was systematically reviewed in the current study, POM was shown to enhance performance and alleviate muscle fatigue and soreness using intermittent running ${ }^{(28,35)}$ and strength exercises $^{(17,18,25,33)}$; to blunt muscle damage following 
weightlifting exercises ${ }^{(18)}$; to promote an antioxidant effect following exhaustive strength exercises ${ }^{(19)}$ treadmill running ${ }^{(27,34)}$ and ultra-endurance exercise ${ }^{(26,36)}$; to confer an antiinflammatory effect during exhaustive running exercise ${ }^{(27)}$; and to promote beneficial effects on the cardiovascular system during strength ${ }^{(18,35)}$ and treadmill running exercise ${ }^{(28,34,35)}$.

The positive effects of POM supplementation are likely linked to its high content of polyphenols. Previous studies investigating the effect of polyphenol supplementation have reported increases in BF, vessel dilation ${ }^{(67)}$ and endothelial function ${ }^{(71)}$. This potential for enhanced vasodilation following polyphenol supplementation could improve nutrient delivery to and promote the efflux of noxious metabolic by-products from skeletal muscle which might have implications for accelerating muscle recovery ${ }^{28,37)}$. In addition to enhanced cardiovascular function, polyphenol supplementation protects against the development oxidative stress $^{(72)}$ and inflammation ${ }^{(71)}$. Accordingly, POM supplementation might aid exercise performance and recovery by enhancing cardiovascular function and mitigating oxidative stress and inflammation. In particular, the ergogenic and recuperative effects of POM supplementation might be linked to the scavenging of free radicals ${ }^{(73)}$. Specifically, polyphenols can attenuate oxidative damage through the rapid donation of an electronto a free radical from $-\mathrm{OH}$ groups $^{(74,75)}$. Therefore, polyphenols are capable of reducing, stabilising and inactivating free radicals species, thereby inhibiting lipid peroxidation and preventing against atherosclerosis and long-lasting $\mathrm{Ca}^{2+}$ release events $^{(76,77)}$. Furthermore, modulating antioxidant enzymes and chelating metal ions $\left(\mathrm{Fe}^{2+}, \mathrm{Cu}^{2+}\right.$; involved in free radical production), and the associated blunting of free radical production, are reported to be among the most important mechanisms mediating the protective effect of polyphenol-rich foods ${ }^{(78,79)}$. Other possible mechanisms by which polyphenol-rich supplements exert their beneficial effects are thought to include the inhibition of leucocyte immobilisation and xanthine oxidase $\operatorname{activity}^{(74)}$; enhanced endothelial and mitochondrial function ${ }^{(80)}$; and the recycling of antioxidant and reducing agents to boost antioxidant defence systems (e.g. vitamins E and C) ${ }^{(73,79)}$.

The potential significance of polyphenols in mediating the positive physiological effects of POM supplementation is supported by observations that the variable polyphenol content of the POM supplements administered and the daily dose of POM consumed (presented in Tables 1 and 2) might influence the inter-study disparity in the efficacy of POM supplementation. For example, the consumption of natural POMj containing $2.56 \mathrm{~g}$ total polyphenols $/ 0.5$ litre three times per $\mathrm{d}(3 \times 250 \mathrm{ml})$ during the $48 \mathrm{~h}$ period prior exercise has been reported to confer anti-damaging effects (i.e. acute and delayed) in responses to intense weightlifting exercise ${ }^{(18)}$. Conversely, the consumption of a commercially produced POM (Wonderful Bottle) that contained only $0.65 \mathrm{~g}$ total polyphenols $/ 0.5$ litre two times per d $(2 \times 250 \mathrm{ml})$, did not influence muscle damage following unilateral eccentric exercise ${ }^{(25)}$. These results imply that $750 \mathrm{ml}$ of polyphenol-rich POMj (>0.7 g/0.5 litre) could be an important dosing threshold for POMj supplementation to confer anti-damaging effects during exercise. Similarly, the nature of exercise was also identified as an important mediator of the positive physiological effects of POM. Indeed, based on the existing evidence it appears that despite the enhanced physiological strain (large degree of muscle, cellular and oxidative damage) with eccentric exercise ${ }^{(81-84)}$ and the potential for POM to attenuate this, benefits of POM supplementation were minimised following eccentric exercise compared to weightlifting one. Nevertheless, it should be acknowledged that many other factors could underlie the disparate inter-study results including the training status of the subjects (untrained $v$. trained), the type of exercise assessed (unilateral eccentric, weightlifting and running treadmill), and the duration of the investigation ( $30 \mathrm{~min}, 48 \mathrm{~h},>1$ week). Therefore, standardising these factors in future studies is important to resolve the potential efficacy of POM supplementation to enhance exercise performance, physiology and recovery and to optimise recommendations for best practice with POM supplementation.

Although consumption of polyphenol-rich beverages (e.g. polyphenols specific to POM, including flavonols, ellagitannins and anthocyanins) can modulate oxidative stress, muscle damage, inflammation and improve cardiovascular function and exercise recovery and performance $e^{(18,19,34,67,68,73)}$, it has been reported that a long-term ( 8 weeks) consumption of the polyphenol, trans-resveratrol $(250 \mathrm{mg} / \mathrm{d})$, can blunt the beneficial effects of exercise on the lowering blood pressure, and blood concentrations of several cardiovascular risk factors in elderly men ${ }^{(85)}$. While the exact mechanism mediating the absence of a potential complementary synergy between exercise and resveratrol was not addressed in this study ${ }^{(85)}$, the authors suggested that enhanced antioxidant defence in the resveratrol group may have retarded the exercise-induced increase in maximal oxygen uptake by abrogating $\operatorname{ROS}^{(86,87)}$ which are now recognised as important signalling molecules that contribute to the adaptations to exercise training ${ }^{(88)}$. Taken together, the results of the available studies indicate that, while the powerful antioxidant effect of polyphenols can blunt redox perturbation and muscle damage, and accelerate the recovery of skeletal muscle force production post-strenuous exercise in the short term, the long-term effects of continuous polyphenol supplementation and the accompanying antioxidant effect could disrupt some of the physiological adaptations elicited by a training program. These findings suggest a balance exists between the beneficial and undesirable effects of polyphenol supplementation which requires consideration in future research. Specifically, it is unclear whether the polyphenol blend that comprises POM promotes a similar blunting in exercise training adaptations as the polyphenol, resveratrol and what supplementation strategy with POM might optimise the balance between promoting recovery from specific training sessions without attenuating the exercise-induced redox signalling that provokes the physiological adaptations to exercise training. This requires addressing in future studies to optimise POMj supplementation guidelines.

Comparison between the effect of pomegranate and other nutritional interventions during exercise

It has been well established in sedentary individuals that POM possesses a higher antioxidant capacity compared to other 
supplement such as red wine, blueberry juice, cranberry juice, orange juice, green tea and wine vinegars ${ }^{(16,51,89)}$. Similarly, POM supplementation has shown potential to enhance muscle performance as evidenced by reduced DOMS, muscle damage, oxidative stress and inflammation, and improved cardiovascular responses during and following exercise ${ }^{(17-19,25-27,32)}$. Nevertheless, it should be acknowledged that other dietary supplementation strategies have also exhibited similar ergogenic and protective effects during exercise. Conversely, supplementation with vitamin $\mathrm{C}$ or $\mathrm{E}$ does not influence strength performance and soreness post exercise ${ }^{(90)}$. Although dietary supplementation with acombination of tocopherols, flavonoids (i.e. hesperetin and quercetin), Se or DHA ${ }^{(63)}$, and the mixture of ascorbic acid, $\alpha$-tocopherol, and $\mathrm{Se}^{(91)}$, can attenuate systematic inflammation (CRP and IL-6) and oxidative stress after eccentric exercise, the effect of this nutrient combination on strength performance and DOMS has yet to be assessed. On the other hand, polyphenols specific to POM, including flavonols, ellagitannins and anthocyanins have demonstrated a positive effect on endothelial-dependent vasodilation, and importantly, this effect is greater than achieved with other fruits containing a different mix of polyphenols ${ }^{(92)}$. Polyphenol supplementation from tart cherries has been shown to improve strength recovery following a bout of eccentric elbow flexion contractions (i.e. lower strength loss and pain ${ }^{(93)}$ ), completion of a marathon (i.e. faster recovery of isometric strength $\left.{ }^{(94)}\right)$ and prolonged, intermittent shuttle exercise (i.e. faster recovery of performance indices $\left.{ }^{(95)}\right)$. The enhanced recovery of muscle function after ingesting tart cherries was accompanied by increased TAC, and lower lipid peroxidation (TBARS) and attenuated inflammation markers (IL-6 and CRP) ${ }^{(94,95)}$. However, no other indices of muscle damage (CK and $\mathrm{LDH}$ ), or oxidative stress (total lipid hydroperoxide (LOOH) and $\mathrm{PC}$ ) were different between the PLA and the cherry juice groups ${ }^{(94,95)}$. In addition, consumption of multi-ingredient performance supplements $30 \mathrm{~min}$ before exercise for 8 weeks has been shown to improve bench press strength, lean body mass and quadriceps muscle thickness without impacting leg press strength ${ }^{(96)}$. Collectively, these results suggest that POM supplementation could be an effective treatment to improve performance, muscle recovery and to reduce weakness and damage in responses to physical exercise. It also appears that POM supplementation compares favourably with other polyphenol-rich foods with regard to enhancing exercise performance and recovery, but further research is required to directly compare the efficacy of POM to enhance exercise performance and recovery compare to other polyphenol-rich foods.

\section{Methodological considerations}

It is important to stress that, while the polyphenol content of $\mathrm{POM}$ is positively associated with its protective effect against damage during exercise and with exercise performance ${ }^{(18,19)}$, POM does not exhibit a uniform polyphenol content throughout the fruit ${ }^{(97)}$. Indeed, higher levels of polyphenols are present in the inner and outer peels than in the seeds ${ }^{(7)}$. These observations underscore the importance of the juice manufacturing method and suggest that POMj/e which contains a mixture of seeds and peels ${ }^{(18,19,26)}$ is more likely to be beneficial for enhancing physiological and functional responses during and following physical exercise. Another important consideration that appears to influence the efficacy of POM supplementation is the supplementation regimen employed. Indeed, it has been reported that POM consumed 30 min before exercise improves intermittent capacity without impacting high-intensity anaerobic performance $^{(32)}$, while POM consumed 60 min prior exercise was able to improve high-intensity anaerobic performance as evidenced by increased total and maximal load lifted during weightlifting exercise ${ }^{(18)}$. Therefore, it would appear advantageous to consume POM supplements at least $60 \mathrm{~min}$ before intensive anaerobic exercise to provide sufficient time to elicit a potential ergogenic effect on both aerobic and anaerobic performance. However, to optimise supplementation guidelines, the dose-response and pharmacokinetics of POM supplementation must be elucidated. Another important consideration for studies wishing to assess the efficacy of POM supplementation is that the beneficial effect of POM supplementation can persist for up to 3 weeks after consumption ${ }^{(52)}$. Accordingly, when a crossover experimental study design is adopted, the wash out period between supplements should be $>3$ weeks to avoid any potential confounding influence of the POM supplementation, if administered first, on the second supplementation arm of the study. Concerning the selection of biomarkers, it should be acknowledged that since exercise has been shown to provoke muscle damage, inflammation and oxidative modifications to several biological components ${ }^{(20-24,98)}$ and since at least two or more biomarkers has been recommended to accurately infer oxidative, muscle or inflammatory damage ${ }^{(99,100)}$, future studies should use multiple related biomarkers (e.g. at least: MDA and PC to measure oxidative stress; CK and LDH to measure muscle damage and hsCRP, IL-6 and TNF to detect inflammation) to confirm the potential positive effects of POM supplementation on blunting exercise-induced oxidative stress, muscle damage or inflammation. Moreover, given that the effects of polyphenol derivatives (flavonols, ellagitannins, anthocyanins and resveratrol) on the biological response and adaptations to exercise training is controversial $^{(18,19,67,68,85)}$, it is also recommended that future studies investigating the potential synergistic or antagonistic link between exercise adaptations and POM supplementation present the exact composition of polyphenols in POM. This information could help elucidate the mechanisms for the synergistic or antagonistic effects of acute and long term POMj supplementation of exercise performance, recovery and adaptation. At last, given that existing findings evidenced the influence of exercise nature on the potential beneficial effect of $\mathrm{POM}$, it should be also acknowledged that further research is required to address the exercise setting in which POM is more likely to be ergogenic.

\section{Conclusion}

The review indicates that POM has the potential to enhance endurance and strength performance and to expedite post-exercise recovery by conferring antioxidant and anti- 
inflammatory effects and improving cardiovascular responses during and following exercise. However, positive effects of POM supplementation are more likely when POMj contains $>0.7 \mathrm{~g}$ total polyphenols $/ 0.5$ litre, when large muscle mass exercise is engaged and when POMj is ingested at least $60 \mathrm{~min}$ before exercise. Therefore, the inclusion $(750 \mathrm{ml} / \mathrm{d})$ of polyphenol-rich POM in the diet of active people prior ( $60 \mathrm{~min}$ ) and after exercise (during $48 \mathrm{~h}$ ) could be beneficial for their physical performance and muscle recovery during and following the physical tasks. However, further research is required to assess how chronic POM supplementation impacts the physiological and performance adaptations to exercise training to help optimise POM supplementation guidelines for a range of exercise settings.

\section{Acknowledgements}

The authors report no financial support/funding for this study and no specific acknowledgement. The authors alone are responsible for the content and writing of the paper.

A. A. drafted the article. S. J. B., H. C., K. T., M. T. and A. H. revised critically the article. N. S. revised and gave final approval. All authors have read and approved the final version of the manuscript, and agree with the order of presentation of the authors.

On behalf of all authors, the corresponding author states that there is no conflict of interest.

\section{References}

1. Kalaycioğlu Z \& Erim FB (2017) Total phenolic contents, antioxidant activities, and bioactive ingredients of juices from pomegranate cultivars worldwide. Food Chem 221, 496-507.

2. Stover E \& Mercure EW (2007) The pomegranate: a new look at the fruit of paradise. HortScience 42, 1088-1092.

3. EL-Nemr SE, Ismail IA \& Raga M (1990) Chemical composition of juice and seeds of pomegranate fruit. Nabrung $\mathbf{3 4}$, 601-606.

4. Seeram NP, Zhang Y, McKeever R, et al. (2008) Pomegranate juice and extracts provide similar levels of plasma and urinary ellagitannin metabolites in human subjects. $J$ Med Food 11, 390-394.

5. Basu A \& Penugonda K (2009) Pomegranate juice: a hearthealthy fruit juice. Nutr Rev 67, 49-56.

6. Zarfeshany A, Asgary S \& Javanmard SH (2014) Potent health effects of pomegranate. Adv Biomed Res 3, 100.

7. Aviram M, Rosenblat M, Gaitini D, et al. (2004) Pomegranate juice consumption for 3 years by patients with carotid artery stenosis reduces common carotid in tima-media thickness, blood pressure and LDL oxidation. Clin Nutr 23, 423-433.

8. Kaplan M, Hayek T, Raz A, et al. (2001) Pomegranate juice supplementation to atherosclerotic mice reduces macrophage lipid peroxidation, cellular cholesterol accumulation and development of atherosclerosis. J Nutr 131, 2082-2089.

9. Adams LS, Seeram NP \& Aggarwal BB (2006) Pomegranate juice, total pomegranate ellagitannins, and punicalagin suppress inflammatory cell signaling in colon cancer cells. J Agric Food Chem 54, 980-985.
10. Shukla M, Gupta K \& Rasheed Z (2008) Consumption of hydrolyzable tannins-rich pomegranate extract suppresses inflammation and joint damage in rheumatoid arthritis. Nutrition 24, 733-743.

11. Ammar A, Chtourou H, Turki M, et al. (2018) Effect of POM supplementation on biochemical markers in elderly Tunisian population. Alexandria J Med 54, 45-48.

12. Sumner MD, Elliott-Eller M, Weidner G, et al. (2005) Effects of pomegranate juice consumption on myocardial perfusion in patients with coronary heart disease. Am J Cardiol 96, 810-814.

13. Kelawala NS \& Ananthanarayan L (2004) Antioxidant activity of selected food stuffs. Int J Food Sci Nutr 55, 511-516.

14. Afaq F, Malik A \& Syed D (2005) Pomegranate fruit extract modulates UV-B-mediated phosphorylation of mitogenactivated protein kinases and activation of nuclear factor kappa $\mathrm{B}$ in normal human epidermal keratinocytes paragraph sign. Photochem Photobiol 81, 38-45.

15. Huang TH, Yang Q, Harada M, et al. (2005) Pomegranate flower extract diminishes cardiac fibrosis in Zucker diabetic fatty rats: modulation of cardiac endothelin-1 and nuclear factor-kappa B path-ways. J Cardiovasc Pharmacol 46, 856-862.

16. Seeram NP, Aviram M, Zhang Y, et al. (2008) Comparison of antioxidant potency of commonly consumed polyphenolrich beverages in the United States. J Agric Food Chem 56, 1415-1422.

17. Trombold JR, Reinfeld AS \& Casler JR (2011) The effect of pomegranate juice supplementation on strength and soreness after eccentric exercise. J Strength Cond Res 25, 1782-1788.

18. Ammar A, Turki M, Chtourou H, et al. (2016) Pomegranate supplementation accelerates recovery of muscle damage and soreness and inflammatory markers after a weightlifting training session. PLOS ONE 11, e0160305.

19. Ammar A, Turki M, Hammouda A, et al. (2017) Effects of pomegranate juice supplementation on oxidative stress biomarkers following weightlifting exercise. Nutrients 9, E819.

20. Ammar A, Chtourou H, Trabelsi K, et al. (2015) Temporal specificity of training: intra-day effects on biochemical responses and Olympic-weightlifting performances. J Sports Sci 33, 358-368.

21. Ammar A, Chtourou H, Hammouda O, et al. (2016) Relationship between biomarkers of muscle damage and redox status in response to a weightlifting training session: effect of time-of-day. Physiol Int 103, 243-261.

22. Ammar A, Chtourou H, Turki M, et al. (2018) Acute and delayed responses of steroidal hormones, blood lactate and biomarkers of muscle damage after a resistance training session: time-of-day effects. J Sports Med Phys Fitness 58, 980-989.

23. Ammar A, Chtourou H \& Souissi N (2017) Effect of time-ofday on biochemical markers in response to physical exercise. J Strength Cond Res 31, 272-282.

24. Ammar A, Chtourou H, Hammouda O, et al. (2015) Acute and delayed responses of C-reactive protein, malondialdehyde and antioxidant markers after resistance training session in elite weightlifters: effect of time of day. Chronobiol Int 32, 1211-1222.

25. Trombold JR, Barnes JN \& Critchley L (2010) Ellagitannin consumption improves strength recovery $2-3 \mathrm{~d}$ after eccentric exercise. Med Sci Sports Exerc 42, 493-498.

26. Fuster-Muñoz E, Roche E \& Funes L (2016) Effects of pomegranate juice in circulating parameters, cytokines, and oxidative stress markers in endurance-based athletes: a randomized controlled trial. Nutrition 32, 539-545. 
27. Mazani M, Fard AS \& Baghi AN (2014) Effect of pomegranate juice supplementation on matrix metalloproteinases 2 and 9 following exhaustive exercise in young healthy males. $J$ Pak Med Assoc 64, 785-790.

28. Moher D, Liberati A, Tetzlaff J, et al. (2009) Preferred reporting items for systematic reviews and meta-analyses: the PRISMA statement. J Clin Epidemiol 62, 1006-1012.

29. Maher CG, Sherrington C \& Herbert RD (2003) Reliability of the PEDro scale for rating quality of randomized controlled trials. Phys Ther 83, 713-721.

30. Verhagen AP, de Vet HC, de Bie RA, et al. (1998) The Delphi list: a criteria list for quality assessment of randomized clinical trials for conducting systematic reviews developed by Delphi consensus. J Clin Epidemiol 51, 1235-1241.

31. Landis JR \& Koch GG (1977) The measurement of observer agreement for categorical data. Biometrics 33, 159-174.

32. Trexler ET, Smith-Ryan AE \& Melvin MN (2014) Effect of pomegranate extract on blood flow and running time to exhaustion. Appl Physiol Nutr Metab 39, 1038-1042.

33. Machin DR, Christmas KM, Chou TH, et al. (2014) Effects of differing dosages of pomegranate juice supplementation after eccentric exercise. J Physiol 2014, 271959.

34. Tsang C, Wood G \& Al-Dujaili E (2011) Pomegranate juice consumption influences urinary glucocorticoids, attenuates blood pressure and exercise-induced oxidative stress in healthy volunteers. Endocr Abs 25, 139.

35. Roelofs EJ, Smith-Ryan AE, Trexler ET, et al. (2017) Effects of pomegranate extract on blood flow and vessel diameter after high-intensity exercise in young, healthy adults. Eur J Sport Sci 17, 317-325.

36. Naghizadeh-Baghi A, Mazani M \& Shadman-Fard A (2015) Punica granatum juice effects on oxidative stress in severe physical activity. Mater Sociomed 27, 48-51.

37. Hellsten Y, Nyberg M \& Jensen LG (2012) Vasodilator interactions in skeletal muscle blood flow regulation. J Physiol 590, 6297-6305.

38. Ignarro LJ, Byrns RE \& Sumi D (2006) Pomegranate juice protects nitric oxide against oxidative destruction and enhances the biological actions of nitric oxide. Nitric Oxide 15, 93-102.

39. Gibala MJ, MacDougall JD \& Tarnopolsky MA (1995) Changes in human skeletal muscle ultrastructure and force production after acute resistance exercise. J Appl Physiol 78, 702-708.

40. Newham DJ, Mills KR \& Quigley BM (1983) Pain and fatigue after concentric and eccentric muscle contractions. Clin Sci 64, 55-62.

41. Clarkson PM \& Hubal MJ (2002) Exercise-induced muscle damage in humans. Am J Phys Med Rehabil 81, S52-S69.

42. Stupka N, Tarnopolsky MA \& Yardley NJ (2001) Cellular adaptation to repeated eccentric exercise-induced muscle damage. J Appl Physiol 91, 1669-1678.

43. Costa E, Moreira A \& Cavalcanti B (2015) Effect of unilateral and bilateral resistance exercise on maximal voluntary strength, total volume of load lifted, and perceptual and metabolic responses. Biol Sport 32, 35-40.

44. Cheung K, Hume P \& Maxwell L (2003) Delayed onset muscle soreness: treatment strategies and performance factors. Sports Med 33, 145-164.

45. Allen DG (2001) Eccentric muscle damage: mechanisms of early reduction of force. Acta Physiol Scand 171, 311-319.

46. Torres R, Ribeiro F \& Alberto Duarte J (2012) Evidence of the physiotherapeutic interventions used currently after exercise-induced muscle damage: systematic review and meta-analysis. Phys Ther Sport 13, 101-114.

47. Ebbeling CB \& Clarkson PM (1989) Exercise-induced muscle damage and adaptation. Sports Med 7, 207-234.
48. Howatson G \& Van Someren KA (2008) The prevention and treatment of exercise-induced muscle damage. Sports Med 38, 483-503.

49. Leeuwenburgh C \& Heinecke JW (2001) Oxidative stress and antioxidants in exercise. Curr Med Chem 8, 829-838.

50. Powers SK \& Jackson MJ (2008) Exercise-induced oxidative stress: cellular mechanisms and impact on muscle force production. . Physiol Rev 88, 1243-1276.

51. Gil MI, Tomás-Barberán FA \& Hess-Pierce B (2000) Antioxidant activity of pomegranate juice and its relationship with phenolic composition and processing. J Agric Food Chem 48, 4581-4589.

52. Matthaiou CM, Goutzourelas N, Stagos D, et al. (2014) Pomegranate juice consumption increases GSH levels and reduces lipid and protein oxidation in human blood. Food Chem Toxicol 73, 1-6.

53. Aviram M, Dornfeld L, Rosenblat M, et al. (2000) Pomegranate juice consumption reduces oxidative stress, atherogenic modifications to LDL, and platelet aggregation: studies in humans and in atherosclerotic apolipoprotein E-deficient mice. Am J Clin Nutr 7, 1062-1076.

54. Guo C, Wei J \& Yang J (2008) Pomegranate juice is potentially better than apple juice in improving antioxidant function in elderly subjects. Nutr Res $\mathbf{2 8}, 72-77$.

55. Halliwell B, Rafter J \& Jenner A (2005) Health promotion by flavonoids, tocopherols, tocotrienols, and other phenols: direct or indirect effects? Antioxidant or not? Am J Clin Nutr 81, 268S-276S.

56. Pedersen BK \& Hoffman-Goetz L (2000) Exercise and the immune system: regulation, integration, and adaptation. Physiol Rev 80, 1055-1081.

57. Cannon JG \& St Pierre BA (1998) Cytokines in exertioninduced skeletal muscle injury. Mol Cell Biochem 179, 159-167.

58. Malm C, Lenkei R \& Sjodin B (1999) Effects of eccentric exercise on the immune system in men. J Appl Physiol 86, 461-468.

59. Haas T, Milkiewicz M, Davis S, et al. (2000) Matrix metalloproteinase activity is required for activity-induced angiogenesis in rat skeletal muscle. Am J Physiol Heart Circ Physiol 279, H1540-H1547.

60. Zimowska M, Brzoska E \& Swierczynska M (2008) Distinct patterns of MMP-9 and MMP-2 activity in slow and fast twitch skeletal muscle regeneration in vivo. Int J Dev Biol 52, 307-314.

61. Carmeli E, Moas M \& Lennon S (2005) High intensity exercise increases expression of matrix metalloproteinase in fast skeletal muscle fibers. Exp Physiol 90, 613-619.

62. Gohji K, Fujimoto N, Hara I, et al. (1998) Serum matrix metalloproteinase- 2 and its density in men with prostate cancer as a new predictor of disease extension. Int J Cancer 79, 96-101.

63. Phillips T, Childs AC, Dreon DM, et al. (2003) A dietary supplement attenuates IL-6 and CRP after eccentric exercise in untrained males. Med Sci Sports Exerc 35, 2032-2037.

64. MacIntyre DL, Reid WD \& Lyster DM (1996) Presence of WBC, decreased strength, and delayed soreness in muscle after eccentric exercise. J Appl Physiol 80, 1006-1013.

65. Ahmed S, Wang N \& Hafeez BB (2005) Punica granatum L. extract inhibits IL- $1 \beta$-induced expression of matrix metalloproteinases by inhibiting the activation of MAP kinases and NF-kB in human chondrocytes in vitro. J Nutr $\mathbf{1 3 5}$, 2096-2102.

66. Kara E, Ozal M \& Gunay M (2011) Effects of exercise and zinc supplementation on cytokine release in young wrestlers. Biol Trace Elem Res 143, 1435-1440. 
67. Barona J, Aristizabal JC \& Blesso CN (2012) Grape polyphenols reduce blood pressure and increase flow-mediated vasodilation in men with metabolic syndrome 1. J Nutr $\mathbf{1 4 2}$, 1626-1632.

68. Tangney C \& Rasmussen HE (2013) Polyphenols, inflammation, and cardiovascular disease. Curr Atheroscler Rep 15, 324 .

69. Khurana S, Venkataraman K \& Hollingsworth A (2013) Polyphenols: benefits to the cardiovascular system in health and in aging. Nutrients $\mathbf{5}, 3779-3827$.

70. Cockcroft JR (2005) Exploring vascular benefits of endothelium-derived nitric oxide. Am J Hypertens $\mathbf{1 8}$, 177S-183S.

71. García-Lafuente A, Guillamón E, Villares A, et al. (2009) Flavonoids as anti inflammatory agents: implications in cancer and cardiovascular disease. Inflamm Res 58, 537-552.

72. Pandey KB \& Rizvi SI (2009) Plant polyphenols as dietary antioxidants in human health and disease. Oxid Med Cell Longev 2, 270-278.

73. Perron NR \& Brumaghim JL (2009) A review of the antioxidant mechanisms of polyphenol compounds related to iron binding. Cell Biochem Biophys 53, 75-100.

74. Nijveldt RJ, van Nood E, van Hoorn DE, et al. (2001) Flavonoids: a review of probable mechanisms of action and potential applications. Am J Clin Nutr 74, 418-425.

75. Castañeda-Ovando A, Pacheco-Hernández ML \& PáezHernández ME (2009) Chemical studies of anthocyanins: a review. Food Chem 113, 859-871.

76. Kerry NL \& Abbey M (1997) Red wine and fractionated phenolic compounds prepared from red wine inhibit low density lipoprotein oxidation in vitro. Atherosclerosis 135, 93-102.

77. Shirokova N, Kang C, Fernandez-Tenorio M, et al. (2014) Oxidative stress and $\mathrm{Ca}^{2+}$ release events in mouse cardiomyocytes. Biophys J 107, 2815-2827.

78. Korkina LG \& Afanas'ev IB (1997) Antioxidant and chelating properties of flavonoids. Adv Pharmacol 38, 151-163.

79. Fraga CG, Galleano M \& Verstraeten SV (2010) Basic biochemical mechanisms behind the health benefits of polyphenols. Mol Aspects Med 31, 435-445.

80. Scalbert A, Manach C \& Morand C (2005) Dietary polyphenols and the prevention of diseases. Crit Rev Food Sci Nutr 45, 287-306.

81. Camus G, Felekidis A, Pincemail J, et al. (1994) Blood levels of reduced/oxidized glutathione and plasma concentration of ascorbic acid during eccentric and concentric exercises of similar energy cost. Arch Int Physiol Biochim Biophys 102, 67-70.

82. Evans WJ \& Cannon JG (1991) The metabolic effects of exercise-induced muscle damage. Exerc Sport Sci Rev 19, 99-125.

83. Fisher-Wellman K \& Bloomer RJ (2009) Acute exercise and oxidative stress: a 30 year history. Dyn Med 8, 1 .
84. Clarkson PM \& Hubal MJ (2002) Exercise-induced muscle damage in humans. Am J Phys Med Rehabil 81, 52-69.

85. Gliemann L, Schmidt JF, Olesen J, et al. (2013) Resveratrol blunts the positive effects of exercise training on cardiovascular health in aged men. $J$ Physiol 591, 5047-5059.

86. Baar K (2004) Involvement of PPAR $\gamma$ CO-activator-1, nuclear respiratory factors 1 and 2 , and PPAR $\alpha$ in the adaptive response to endurance exercise. Proc Nutr Soc 63, 269-273.

87. Radak Z, Chung HY \& Koltai E (2008) Exercise, oxidative stress and hormesis. Ageing Res Rev 7, 34-42.

88. Jackson MJ (2011) Control of reactive oxygen species production in contracting skeletal muscle. Antioxid Redox Signal 15, 2477-2486.

89. Budak HN \& Guzel-Seydim ZB (2010) Antioxidant activity and phenolic content of wine vinegars produced by two different techniques. J Sci Food Agric 90, 2021-2026.

90. Beaton LJ, Allan DA \& Tarnopolsky MA (2002) Contraction induced muscle damage is unaffected by vitamin E supplementation. Med Sci Sports Exerc 34, 798-805.

91. Goldfarb AH, Bloomer RJ \& McKenzie MJ (2005) Combined antioxidant treatment effects on blood oxidative stress after eccentric exercise. Med Sci Sports Exerc 37, 234-239.

92. Chong MF-F, Macdonald R \& Lovegrove J (2010) Fruit polyphenols and CVD risk: a review of human intervention studies. Br J Nutr 104, S28-S39.

93. Connolly DAJ, McHugh MP, Padilla-Zakour OI, et al. (2006) Efficacy of a tart cherry juice blend in preventing the symptoms of muscle damage. Br J Sports Med 40, 679-683.

94. Howatson G, McHugh MP, Hill JA, et al. (2010) Influence of tart cherry juice on indices of recovery following marathon running. Scand J Med Sci Sports 20, 843-852.

95. Bell PG, Stevenson E, Davison GW, et al. (2016) The effects of montmorency tart cherry concentrate supplementation on recovery following prolonged, intermittent exercise. Nutrients $\mathbf{8}, 441$.

96. Lowery RP, Joy JM, Dudeck JE, et al. (2013) Effects of 8 weeks of Xpand $^{\circledR} 2 X$ pre workout supplementation on skeletal muscle hypertrophy, lean body mass, and strength in resistance trained males. J Int Soc Sports Nutr 10, 44.

97. Kalaycioğlu Z \& Erim FB (2017) Total phenolic contents, antioxidant activities, and bioactive ingredients of juices from pomegranate cultivars worldwide. Food Chem 15 , 496-507.

98. Radak Z, Zhao Z, Koltai E, et al. (2013) Oxygen consumption and usage during physical exercise: the balance between oxidative stress and ROS-dependent adaptive signaling. Antioxid Redox Signal 18, 1208-1246.

99. Halliwell B \& Whiteman M (2004) Measuring reactive species and oxidative damage in vivo and in cell culture: how should you do it and what do the results mean? Br J Pharmacol 142, 231-255.

100. Cobley JN, Close GL \& Bailey DM (2017) Exercise redox biochemistry: conceptual, methodological and technical recommendations. Redox Biol 12, 540-548. 